\title{
A comparison of designer activity using core design situations in the laboratory and practice
}

Cash, Philip; Hicks, Ben J. ; Culley, Steve J.

\section{Published in:}

Design Studies

Link to article, DOI:

10.1016/j.destud.2013.03.002

Publication date:

2013

Link back to DTU Orbit

Citation (APA):

Cash, P., Hicks, B. J., \& Culley, S. J. (2013). A comparison of designer activity using core design situations in the laboratory and practice. Design Studies, 34(5), 575--611. https://doi.org/10.1016/j.destud.2013.03.002

\section{General rights}

Copyright and moral rights for the publications made accessible in the public portal are retained by the authors and/or other copyright owners and it is a condition of accessing publications that users recognise and abide by the legal requirements associated with these rights.

- Users may download and print one copy of any publication from the public portal for the purpose of private study or research.

- You may not further distribute the material or use it for any profit-making activity or commercial gain

- You may freely distribute the URL identifying the publication in the public portal

If you believe that this document breaches copyright please contact us providing details, and we will remove access to the work immediately and investigate your claim. 
A comparison of designer activity using core design situations in the laboratory and practice

Philip Cash ${ }^{1}$, Ben Hicks ${ }^{2}$, Steve Culley ${ }^{2}$

${ }^{1}$ DTU Technical University of Denmark

${ }^{2}$ Department of Mechanical Engineering, University of Bath, Bath, UK

Please cite this article in press as: Cash, P. J., et al., A comparison of designer activity using core design situations in the laboratory and practice, Design Studies (2013), 34, 5, pp. 575-611 http://dx.doi.org/10.1016/j.destud.2013.03.002

Philip Cash,

Department Of Management Engineering,

Section Of Engineering Design and Product Development

Technical University of Denmark

Produktionstorvet

DK-2800 Lyngby, Denmark

Tel: $\quad+4545254550$

Email: pcas@dtu.dk 


\section{A comparison of designer activity using core design situations in the laboratory and practice}

In 2011 one quarter of all articles published in Design Studies and the Journal of Engineering Design used experimental studies. However, there is little work exploring the relationship between laboratory and practice. This paper addresses this by detailing an analysis of designer activity in three situations commonly studied by design researchers: information seeking, ideation and design review. This comparison is instantiated through three complementary studies: an observational study of practice and two experimental studies. These reveal a range of similarities and differences that are described using a mixed methods approach. Based on this it is concluded that laboratory studies are important research tools and that clear and definable relationships do exist between design activity in practice and the laboratory.

Keywords: experiment; designer activity; practice; laboratory; research methods

Experimental studies play a key role in design research, accounting for a quarter of all articles in

Design Studies (7 out of 28) and the Journal of Engineering Design (9 out of 40) in 2011. However, practitioners often perceive there to be a dichotomy between fundamental experimental study and applied, practice based, design research. Friedman (2000) states that "Practitioners sometimes reject vital streams of research while seeking solutions that do work" (p.22). This perspective is further elaborated by Edmonds et al. (2005) who suggest that the underlying failing of experimental study is that the subject is not design practice itself but actually a simulation of practice in an contrived context. As such, a key point of contention can be characterised as the unknown affect that simulation and contrived context have on designer activity.

This type of issue also appears in many fields related to design research. For example, Eifert et al. (1999), in behavioural research, state that the relevance of laboratory based research has been understated due to the gap in understanding external validity. Further, both Bonetti et al. (2010) in behavioural research and Marsden (2007) in education research have adopted the approach of developing intermediary studies - taking an experimental approach into a practice 
context - in order to directly address this gap. Bolton and Ockenfels (2008) describe this as losing control in a controlled way. Although this approach can be important it is most effective when based on substantive theory, allowing key factors to be controlled as well as offering predictions to be examined (Levitt \& List, 2007). As little predictive theory is currently available in design research the authors argue that as a field, we are not yet ready to fully adopt this approach on its own. Instead the authors posit that a more cohesive investigation of laboratory, intermediary and practice based cases offers the best opportunity for developing experimental generalisability as explored by Nordgren and McDonnell (2011).

This approach is based on several key texts in behavioural, educational and economic research. In particular Eifert et al. (1999) and Newman and Cole (2004) utilise studies specifically designed to investigate the gap between laboratory and practice. Further, Levitt and List (2007) and Eifert et al. (1999) identify factors that should be considered in any such study including the population, the realism of the task including what is at stake, the context and the identification of the different variations between laboratory and practice based activity.

Taking these considerations into account this paper will compare designer activity for core design situations in the laboratory and practice, based on the comparative approaches outlined above. As such, the different study contexts will be briefly discussing before the method, results and findings are described in detail.

\section{Study Context}

The two main types of study undertaken in design research can be defined contextually as: practice (Lethbridge, et al., 2005) and laboratory (Torlind, et al., 2009). However, there is a third type that combines elements of both approaches, henceforth referred to as intermediary, building on the work outlined above. Table 1 summarises the relevant characteristics of the three main empirical contexts focusing on their strengths, weaknesses and level of contrivance. 
Table 1: Different contexts of empirical design research

\begin{tabular}{|c|c|c|}
\hline \multirow[t]{4}{*}{ Practice } & Description & $\begin{array}{l}\text { Fully embedded or ethnographic study of practice and practitioners, typically } \\
\text { observational (Ball \& Ormerod, 2000) }\end{array}$ \\
\hline & $\begin{array}{l}\text { Level of } \\
\text { contrivance }\end{array}$ & $\begin{array}{l}\text { Few contrived elements - equipment or researchers are typically fully } \\
\text { embedded (Lethbridge, et al., 2005) }\end{array}$ \\
\hline & Strengths & $\begin{array}{l}\text { Can give realistic information on the behaviour/activities of practitioners in } \\
\text { their natural environment ( } \mathrm{H} \text {. Robinson, et al., 2007) }\end{array}$ \\
\hline & Weaknesses & $\begin{array}{l}\text { Context specific, complex, typically only be used to describe existing systems, } \\
\text { difficult to establish causal relationships (Button, 2000) }\end{array}$ \\
\hline \multirow[t]{4}{*}{ Intermediary } & Description & $\begin{array}{l}\text { Experimental studies using practitioners, varying little from normal practice, } \\
\text { some times known as quasi-experiments (Cook, et al., 1979) }\end{array}$ \\
\hline & $\begin{array}{l}\text { Level of } \\
\text { contrivance }\end{array}$ & $\begin{array}{l}\text { Few contrived elements - typically limiting variation to a few aspects such as } \\
\text { task or participants (Howard, et al., 2010) }\end{array}$ \\
\hline & Strengths & $\begin{array}{l}\text { Information can be related to practice and the laboratory due to varying levels } \\
\text { of contrivance (Shadish, et al., 2002) }\end{array}$ \\
\hline & Weaknesses & $\begin{array}{l}\text { Difficult to carry out, limited scope for variation, limited scope for isolation of } \\
\text { individual variables or relationships (Shadish, et al., 2006) }\end{array}$ \\
\hline \multirow[t]{4}{*}{ Laboratory } & Description & $\begin{array}{l}\text { Experimental studies typically not using practitioners, in a custom } \\
\text { environment (Torlind, et al., 2009) }\end{array}$ \\
\hline & $\begin{array}{l}\text { Level of } \\
\text { contrivance }\end{array}$ & $\begin{array}{l}\text { Numerous contrived elements - typically using students, different } \\
\text { environments or methods (Corremans, 2009) }\end{array}$ \\
\hline & Strengths & $\begin{array}{l}\text { Can be highly constrained, can isolating important variables or mechanisms, } \\
\text { can explore causal relationships (Shadish, et al., 2002) }\end{array}$ \\
\hline & Weaknesses & $\begin{array}{l}\text { Difficult to relate to practice due to highly contrived nature, complex to setup } \\
\text { and to carry out effectively (Levitt \& List, 2007) }\end{array}$ \\
\hline
\end{tabular}

A cohesive investigation of laboratory, intermediary and practice offers the possibility of understanding the gaps/links between these contexts while supporting the creation of strong and credible relationships and providing a basis for theory development/testing (Bolton \& Ockenfels, 2008; Nordgren \& McDonnell, 2011). This is further illustrated in political science by the development of Duverger's Law (Reed, 1990) or the seminal work of Vygotski and Cole (1978) who discuss the development of 'law-like' relations in psychology. Critically, each of these works identified key situations commonly examined in both practice and laboratory as the focus of their comparison efforts. Based on this finding, this work adopts a similar approach to developing and testing such relationships for design research. Thus, the first step in this process is to identify key situations - subsequently referred to as core design situations - suitable for developing the comparison.

\section{Core Design Situations}

Core Design Situations are used in this study to represent situations that are: 
- Core to the design process.

- Commonly studied in both practice and the laboratory.

- Have discreet elements that can be replicated experimentally.

These differ from 'critical situations' (Badke-Schaub \& Frankenberger, 1999), which focus on the design process. Instead situations are termed core where they provide key instances where design activity can be directly compared for both practice and laboratory based empirical design research, focusing on the research aspect. Based on these criteria, three core situations were identified - information seeking, ideation and design review.

\section{Approach}

In order to effectively compare one situation to another, the input (or action) must be similar if not the same. As such, for a comparison to practice, a number of core situations from practice can be used to form the source for the laboratory-based aspect of the comparison. Based on this, it is then possible to compare the two situations and build up an empirically supported relationship. In this case actions are considered to be analogues while context and output are explicitly comparable (solid arrow - Figure 1). From this an implicit comparison of mechanisms can be established (dashed arrow - Figure 1). Using this theoretical model a three-stage approach is defined allowing for direct and indirect comparison between practice and laboratory using a third context - the intermediary case (defined as: experimental studies using practitioners with only limited variation from normal practice). In this way the study compares design in practice and the laboratory by capturing how design unfolds in practice (extracted in form of core situations) and then replicating these situations in a laboratory context. Finally, in order to give a common reference frame - essential for the comparison - analysis is focused on the designer activity. 
Figure 1: Building comparisons using three linked contexts

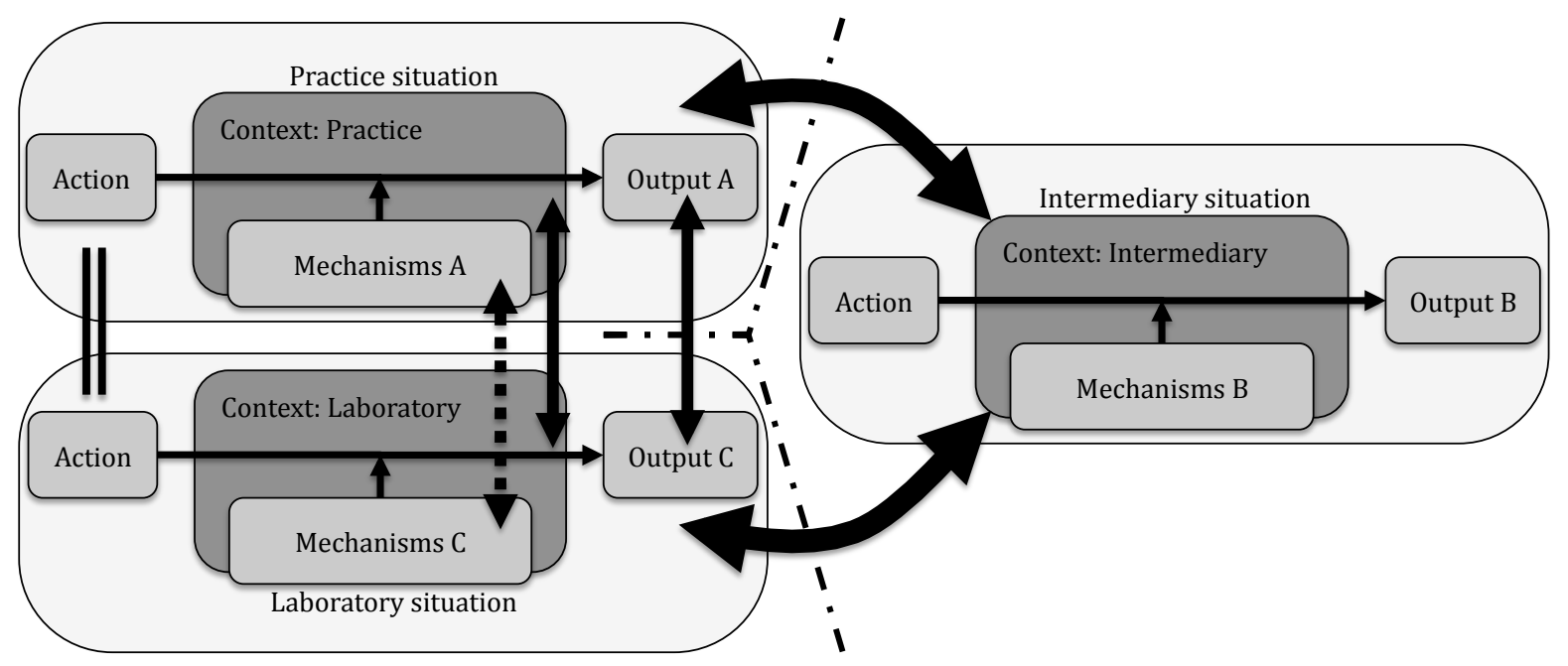

Based on this approach five key steps were identified for the characterisation and validation of the comparison between laboratory and practice:

(1) Study 1: An observational study of practice.

(2) Analysis: Identification and contextualisation of core design situations.

(3) Study 2: A laboratory-based study of the core design situations.

(4) Study 3: An intermediary study of the core design situations.

(5) Analysis: The triangulation of the three studies to give a detailed comparison.

It is important to note that by adopting this approach i.e. building on and explicitly testing existing theory via the comparison of contexts this study can be characterised as theory testing with respect to Eisenhardt and Graebner's (2007) well established work on theory building. As such, the work is complementary to grounded studies, which can be characterised as theory building. In order to implement the five steps it is first necessary to describe the specific methods used to carry out the comparison studies. The method outlined in Sections 2.1 to 2.3 has been summarised for brevity and has been developed from (Cash, et al., 2010; 2011).

\subsection{Capture}

The capture strategy focused on capturing participants' interactions and activity using a number of 
complementary technologies. Webcams were used to capture all participant activity within the work area, computer usage (screen capture and overall usage) and logbooks were also captured using the Panopto software (2011) and LiveScribe pen (2011) respectively. Finally, mobile (participant mounted) cameras were used to capture interactions away from the primary work area as well as fixed cameras located in the various meeting rooms at the SME and in the laboratory. Figure 2 shows the setup for individual and group activities (cameras are represented by triangles - indicating their orientation).

Figure 2: Technical setup for individual and group activities
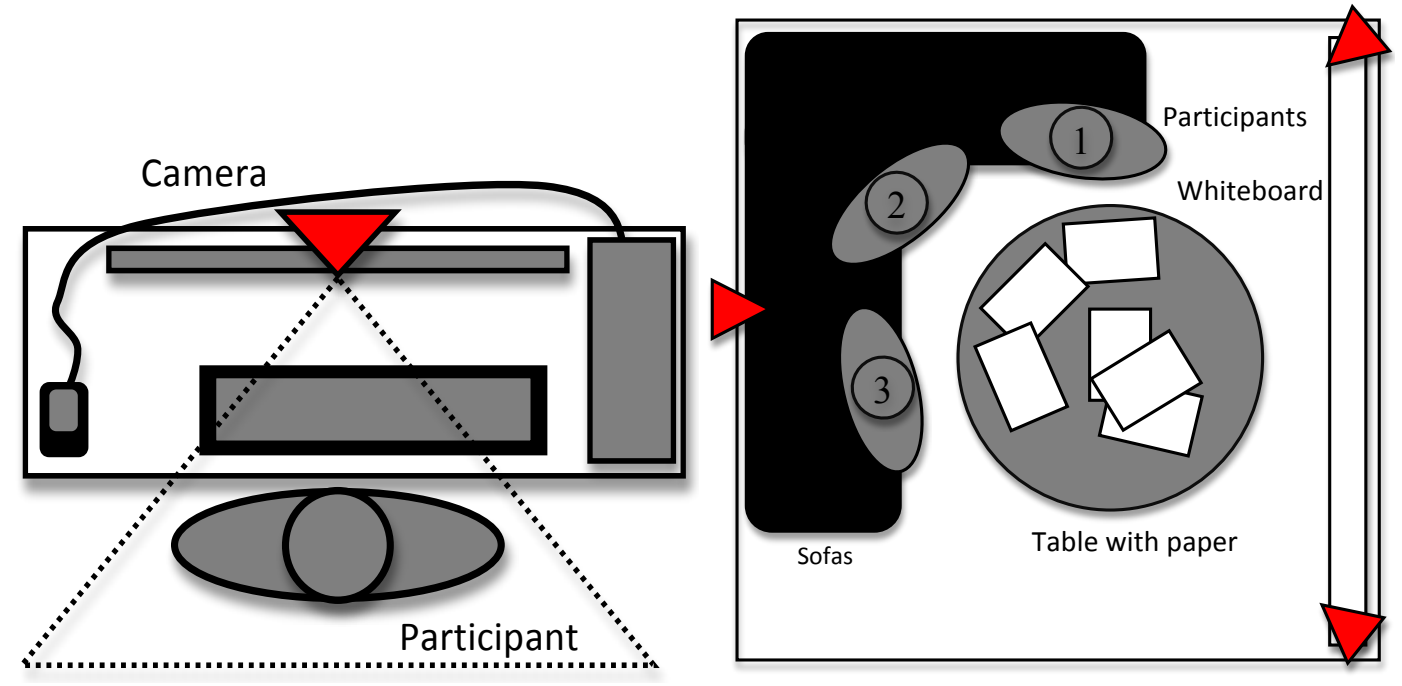

\subsection{Coding}

Coding was carried out using the VCode software (Hagedorn, et al., 2008; 2011). This allowed the multiple capture streams to be combined and synchronously coded. Coding took place in two major stages: general codes were used to define a number of core design situations before more detailed codes were used to record detailed designer activity. The first stage used the codes outlined in Table 2 to characterise the whole study period and subsequently identify core design situations as defined in Section 1. 
Table 2: Situational codes

\begin{tabular}{|c|c|c|}
\hline Group & Code & Definition \\
\hline \multirow[t]{7}{*}{ Situation } & Individual & No real time interaction with any other individual or group \\
\hline & Group & Real time interaction with one or more other individuals \\
\hline & Synchronous & No delays between communications \\
\hline & Asynchronous & Significant delays (longer than a few seconds) between communications \\
\hline & Co-located & Working in the same location at the time of an interaction \\
\hline & Distributed & Working in different locations at the time of an interaction \\
\hline & Location & The specific location of the participant in their main work site \\
\hline \multirow[t]{4}{*}{ Subject } & $\begin{array}{l}\text { Design process } \\
\text { stage }\end{array}$ & $\begin{array}{l}\text { The stage at which an interaction is taking place within the associated project - see } \\
\text { Hales (1991) for stage definitions }\end{array}$ \\
\hline & People & $\begin{array}{l}\text { The subject of an interaction includes: personnel, personal, managing people, } \\
\text { customers }\end{array}$ \\
\hline & Product & $\begin{array}{l}\text { The subject of an interaction includes: prototypes, design documents, project } \\
\text { management }\end{array}$ \\
\hline & Process & $\begin{array}{l}\text { The subject of an interaction includes: resources/time allocation, scheduling, stage } \\
\text { gate management }\end{array}$ \\
\hline
\end{tabular}

The second stage consisted of the detailed characterisation of each core situation. Table 3 defines

the codes used for this, that are common across all the core design situations. Additional, situation

specific, codes were used to further detail each situation, but as these are not common they are

defined in Section 3.1 - in relation to their associated situation.

Table 3: Detailed codes

\begin{tabular}{|c|c|c|}
\hline Group & Code & Definition \\
\hline \multirow{8}{*}{$\begin{array}{l}\text { Problem } \\
\text { solving }\end{array}$} & Goal setting & Identifying where the design is and where it needs progressing to \\
\hline & Constraining & Imposing boundaries with requirements and desirables \\
\hline & Exploring & Discussing possibilities and ideas invoking suggestions \\
\hline & Solving & Involves searching, gathering, creating, developing solutions \\
\hline & Evaluating & Judging the quality, value and importance of something \\
\hline & Decision making & Considering key factors from evaluation and possible compromises to form decisions \\
\hline & Reflection & Reflecting upon a design decision or process already adopted or occurred \\
\hline & Debating & Discussing opposing views \\
\hline \multirow{9}{*}{$\begin{array}{l}\text { Information } \\
\text { transaction }\end{array}$} & Recognising need & Recognising a problem or deficit \\
\hline & Seeking & Finding information \\
\hline & Requesting & Direct requests to another party to provide information \\
\hline & Interpretation & Assigning meaning or value to information \\
\hline & Validation & Checking the authenticity or value of information \\
\hline & Informing & Using information to inform one or more people \\
\hline & Clarifying & Using information specifically to resolve issues or clarity problems \\
\hline & Confirming & Using information specifically to affirm or confirm a issue or point \\
\hline & Managing & $\begin{array}{l}\text { Specifically arranging, directing or instructing with regards to people, product or } \\
\text { process }\end{array}$ \\
\hline \multirow[t]{4}{*}{$\begin{array}{l}\text { Giving / } \\
\text { asking }\end{array}$} & Opinion & $\begin{array}{l}\text { Giving or receiving opinions: includes evaluation, analysis, expression of feeling or } \\
\text { wish }\end{array}$ \\
\hline & Orientation & $\begin{array}{l}\text { Giving or receiving orientation or scene setting: includes information, repetition, } \\
\text { confirmation }\end{array}$ \\
\hline & Suggestion & $\begin{array}{l}\text { Giving or receiving direction or proposed possibilities: includes direction, possible } \\
\text { modes of action }\end{array}$ \\
\hline & Agree/disagree & $\begin{array}{l}\text { The participant shows passive acceptance/rejection, understands, concurs, } \\
\text { complies/formality, withholds resources }\end{array}$ \\
\hline
\end{tabular}




\begin{tabular}{|l|l|l|}
\hline & $\begin{array}{l}\text { Antagonism/ } \\
\text { solidarity }\end{array}$ & $\begin{array}{l}\text { Giving or receiving support/criticism: increases/decreases others status, gives help or } \\
\text { rewards others/asserts or defends self }\end{array}$ \\
\cline { 2 - 3 } & $\begin{array}{l}\text { Tension/ tension } \\
\text { release }\end{array}$ & The participants jokes, laughs, shows satisfaction/asks for help, withdraws \\
\hline
\end{tabular}

\subsection{Analysis}

For each core design situation, there were three major areas of analysis suitable for developing a comparison of the various contexts (practice, intermediary and laboratory). These were:

- The focus of the participants' activity.

- The profile of activity over time.

- Situation specific activity.

These areas allow for a multifaceted comparison of the participants' activity while supporting a multi-level comparison from general to situation specific.

\section{Statistical Significance}

As there are not sufficient data points to use statistical significance tests to determine differences between contexts, maximum and minimum values were used as a quantitative guide for the qualitative analysis. Throughout this paper the convention of referring to a difference as substantial has been adopted where values fall outside the maximum/minimum range found in the laboratory. This coupled with a comparison against the results from practice gives an indication of how closely related the contexts are.

\section{Study 1: Observational study in practice context}

Study 1 served two roles within this work. Firstly, an observational characterisation of designer activity was used to provide the benchmark for practice and secondly it was used to identify the core design situations. An observational approach was adopted in order to capture uncontrived situations in practice and avoid altering the designers' activity. 
The population for this study was introduced to the research through a series of introductory meetings whilst maintaining participant hypothesis blindness (Wilkinson, 1999). Based on these meetings and a questionnaire-based analysis three participants were selected as a suitable representation of the population of seven engineers. As such, participants were asked to volunteer without further screening to avoid possible selection bias (Torgerson \& Torgerson, 2003) and due to the ethical implications of observation. Following this, three of the five volunteers were randomly selected for the study. Thus, the final selected population consisted of one junior, one midlevel and one more senior practitioner. At this stage, it is important to note that a fully randomised selection regime would have offered the best possible approach (Torgerson \& Torgerson, 2003) but was not possible due to the level of observation involved. As such, although some bias may have been introduced through voluntary selection, it was the best pragmatic option available and is partially mitigated by the homogeneity of the population. Once selected, each participant was randomly assigned a study start date. Each study consisted of two parts: an acclimatization period ( 3 weeks) and a study period ( 1 week).

Acclimatization allowed the participants to become used to the capture procedure and return to their normal working habits after the disruption of the equipment setup (Adair, 1984; Leonard \& Masatu, 2006; Podsakoff, et al., 2003). Participant feedback and analysis of the gathered data from this period was used to check the effectiveness of the capture method and to ensure participants' had returned to their normal working habits. Once acclimatization was complete each participant undertook one full week of study.

\section{Situation Specific Codes}

In terms of information seeking two primary codes were identified - finding source and finding information within source based on Robinson (2010). These were complemented by codes for the sources used, going beyond Robinson's definition of the Internet as a single source. For ideation 
only a one code was added to examine idea generation based on Howard et al. (2010). Finally, for

the design review situation codes were added to identify artefact use based on Huet et al. (2007).

Additional refinement was carried out to ensure the codes were relevant for the study tasks and

context. All the stage specific codes are defined in Table 4.

Table 4: Situation specific codes

\begin{tabular}{|c|c|}
\hline Code & Definition \\
\hline \multicolumn{2}{|r|}{ Information Seeking } \\
\hline Find source & Searching for information relating to where specific product information is available \\
\hline Find within source & Searching within a specific website for information related to the product \\
\hline Search engine & A website that retrieves data, files or documents form the whole internet \\
\hline Catalogue & $\begin{array}{l}\text { A website that provides a list of items, specifically for sale - entries can also include technical } \\
\text { information }\end{array}$ \\
\hline $\begin{array}{l}\text { Technology } \\
\text { article/blog }\end{array}$ & $\begin{array}{l}\text { A website giving general commentary on products, technologies and other technical literature } \\
\text { in an informal manner }\end{array}$ \\
\hline Supplier article & $\begin{array}{l}\text { A website giving commentary on products or technologies written and hosted by the supplier of } \\
\text { said product/technology etc. }\end{array}$ \\
\hline Forums & A website hosting a message board \\
\hline Expert/supplier & A specific acknowledged expert or product supplier \\
\hline Social media & A website hosting user uploaded and accessible content for the purposes of social interaction \\
\hline Wiki & $\begin{array}{l}\text { A website developed collectively which allows users to add and edit content but with a specific } \\
\text { focus such as informing }\end{array}$ \\
\hline Patent & A website displaying a specific patent document \\
\hline Standard & A website displaying a specific standard such as the British standards \\
\hline \multicolumn{2}{|r|}{ Ideation } \\
\hline Idea & A novel concept - not previously mentioned - relating to some aspect of the product/solution \\
\hline \multicolumn{2}{|r|}{ Design Review } \\
\hline Office & The use of elements in the office environment itself e.g. using a built in whiteboard \\
\hline Drawing & Interacting with or producing formal technical drawings \\
\hline Calculation & Interacting with or producing specific calculations \\
\hline Communication & Interacting with or producing formal communications outside of the meeting e.g. email \\
\hline Component & Interacting with an existing physical component \\
\hline Testing/test results & Using data from previous testing or conducting ad hoc tests within the meeting \\
\hline Sketching & Interacting with or producing out informal drawings \\
\hline Logbook records & Interaction with notes made in the logbook previously \\
\hline
\end{tabular}

\section{Studies 2 and 3: Experimental studies in the laboratory and intermediary}

\section{contexts}

The method used to carry out Studies 2 and 3 was analogous (to allow comparison) with only two major factors differentiating them - population and setting. Therefore, this section outlines the common elements before detailing the specific differences. 


\subsection{Common experimental method}

The method used for Studies 2 and 3 sought to replicate the core design situations identified in Study 1 in a cohesive and linked manner. As such, the experimental method had four stages linked by a common design problem, which was introduced to the participants incrementally - with increasingly specific briefing information provided at each stage. This allowed the participants to be artificially moved through the stages in the design process. The four stages were as follows and are summarised in Figure 3:

(1) Stage 1: 50 min - individual information seeking based on an initial broad brief.

(2) Stage 2: $50 \mathrm{~min}$ - team ideation session based on a preliminary specification.

(3) Stage 3: $90 \mathrm{~min}$ - individual detailed design development based on a detailed brief.

(4) Stage 4: $50 \mathrm{~min}$ - team design review and selection session using all the given information. A team leader is randomly assigned at this stage, denoted by the black circle in Figure 3.

Figure 3: Experimental structure in four stages

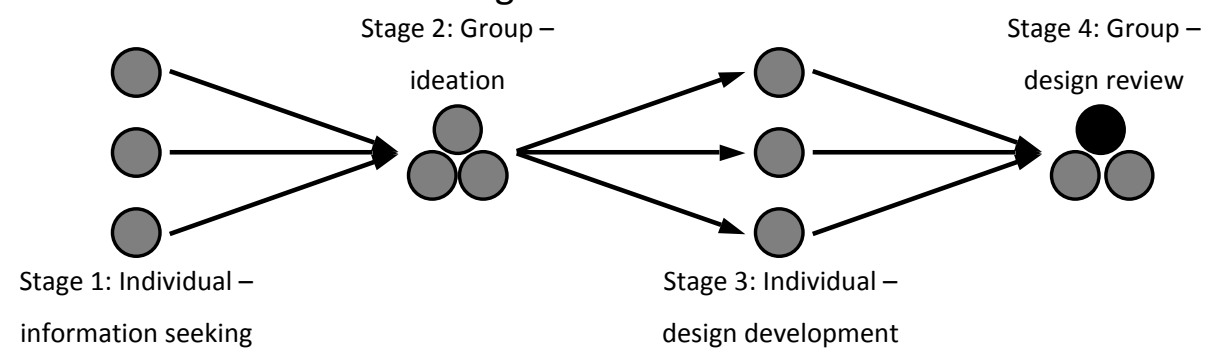

A team leader was nominated for the final stage to ensure that the participants stayed on task and to reflect the difference in seniority and leadership encountered during Study 1 . Table 5 outlines the key differences between the situations recorded in practice and those undertaken experimentally.

Table 5: Practice and experimental tasks

\begin{tabular}{|l|l|l|l|}
\hline Core situation & Task from practice & Experimental task & Stage \\
\hline \hline $\begin{array}{l}\text { 1. Information } \\
\text { seeking }\end{array}$ & $\begin{array}{l}\text { A representative period of individual } \\
\text { information seeking - specifically for } \\
\text { feasibility level technical details of an } \\
\text { electrical component }\end{array}$ & $\begin{array}{l}50 \text { minutes of individual information } \\
\text { seeking - specifically for feasibility level } \\
\text { technical information on camera } \\
\text { mounting devices }\end{array}$ & 1 \\
\hline 2. Ideation & A typical 3 person ideation activity - & 50 minutes of 3 person ideation activity - & 2 \\
\hline
\end{tabular}




\begin{tabular}{|c|c|c|c|}
\hline & $\begin{array}{l}\text { specifically focusing on product ideas for } \\
\text { measurement of water use }\end{array}$ & $\begin{array}{l}\text { specifically focusing on product ideas for } \\
\text { mounting a camera on a balloon }\end{array}$ & \\
\hline No core situation & $\begin{array}{l}\text { No specific period used - based on } \\
\text { typical design development activities }\end{array}$ & $\begin{array}{l}90 \text { minutes of individual design } \\
\text { development - taking one mounting } \\
\text { concept to prototype level of detail }\end{array}$ & 3 \\
\hline 3. Review meeting & $\begin{array}{l}\text { A typical } 2 \text { person review meeting (with a } \\
\text { clear meeting leader) - specifically } \\
\text { focusing on test results, product planning } \\
\text { and selection for prototyping }\end{array}$ & $\begin{array}{l}50 \text { minutes of } 3 \text { person review and } \\
\text { selection - specifically focusing on } \\
\text { selecting a concept for further } \\
\text { prototyping }\end{array}$ & 4 \\
\hline
\end{tabular}

As Stage 3 was not based on a core situation, the results for this stage were not used for comparison. Instead, Stage 3 was used purely as a preliminary step to setup Stage 4, allowing the participants to develop individual ideas prior to the design review. The full detail of the specific tasks and briefing documents given to the participants is included in the Appendix. For both studies technical setup was as shown in Figure 2.

\subsection{Specific differences}

The two key differences between Study 2 and Study 3 are the population used and the setting.

In terms of the population, Study 2 used student engineers while Study 3 used three randomly selected participants from the population of practitioners used for Study 1 . The students were selected from final year candidates on the University of Bath, Mechanical Engineering (MEng) degree course. A naturally occurring subgroup within this was the product design and development module (40 students). Selecting from this group ensured familiarity with the tasks to be undertaken e.g. brainstorming. Further, it ensured that age, academic focus, educational background and sociometric factors were relatively similar while also forming an acceptable representation of the larger student body. Twelve students were randomly selected and split into four teams of three. A team size of three was selected as it fulfilled the demands of representativeness (Cash, Elias, et al., 2011), whilst also allowing for effective comparison to the activities of the practitioners in Study 1. 
In terms of setting, Study 2 was set in a specifically instrumented workspace at the University of Bath while Study 3 was setup in situ at the SME, where the participants could work at their own desks.

\subsection{The studies}

The two previous sections have explained the methods used for the three studies. These are then applied to the core design situations: Information seeking, ideation and design review. These are dealt with in sections 5, 6 and 7 respectively. The following abbreviations are used for brevity in all the figures: lab denotes the laboratory context; int denotes the intermediary context; and practice denotes the practice context

\section{Core Design Situation 1: Information seeking}

Examining each form of analysis in turn (focus of activity, activity over time and situation specific activity), it is possible to build up a detailed comparison of practice and laboratory.

\subsection{Focus of Activity}

As outlined in Section 1.3 the first area of comparison is in the focus of the participants' activity explored in Figure 4.

Firstly, for 'seeking information' both intermediary and laboratory contexts were greater (averaging 57\% and 60\% respectively) than in practice (41\%), although all results fell within the range seen in the laboratory (26\% minimum). However, a larger difference was observed for 'interpreting', where the minimum laboratory value (13\% duration) was greater than in practice (6\% duration, $2 \%$ instances), which was substantially lower than the mean values for the intermediary (32\% duration, $13 \%$ instances) and laboratory (40\% and $11 \%)$. 
Secondly, Figure 4 emphasises the primacy of 'catalogues' as the main source of information across all contexts, with the minimum usage in the intermediary (15\% duration, $12 \%$ instances) still being substantially greater than for any other individual source.

Finally, the figure shows 'finding source' and 'finding within source' averaging $22 \%$ and $49 \%$ of participants' time in the laboratory respectively - a ratio very similar to that seen in practice (15\% and $41 \%)$. An example of the discriminatory role of the intermediary results can be seen in 'interpreting' - here the laboratory and intermediary results are aligned while practice is lower. As such, we can conclude that this difference is unlikely to be caused by changes in the participants or the setting and thus, must be attributed to other factors.

Figure $4 c$ shows that, other than in a very small number of cases, the average time spent on a source is short across all contexts, with $79 \%$ of the activities averaging less than 50 seconds. However, for 'requesting information' the intermediary and laboratory contexts were lower than practice-based participants who averaged 90 seconds per instance.

Figure 4: a) Coded activity duration as a percentage of the total situation time, b) number of instances and c) mean time per instance

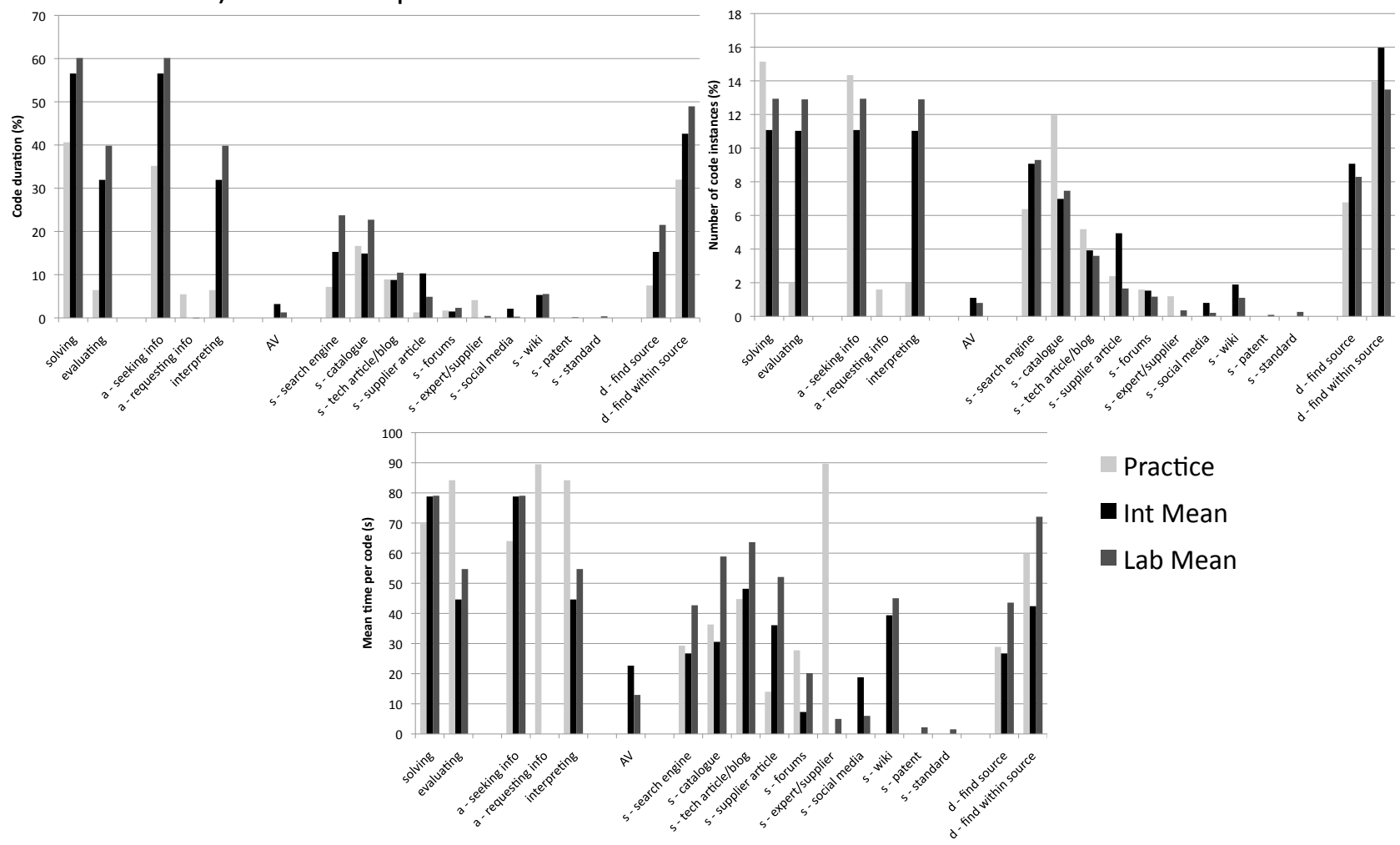


Overall the laboratory mean averages $7.3 \%$ greater duration than practice. This can be attributed to the wider scope of activity in practice and that a larger proportion of time is accounted for in breaks and miscellaneous tasks. This is further supported by the intermediary study, which closely matches the laboratory (averaging $2.2 \%$ less than the laboratory mean). Unlike 'total duration' there do not appear to be any clear trends across contexts associated with 'total number of instances' or 'average time per instance'. These highlight that the activities 'requesting information' and 'expert/supplier' (5.5\% and $4.1 \%$ of situation duration respectively) play a less important role in the other contexts compared to practice. This emphasises that, as practice operates over longer timescales, a larger weight is placed on interpersonal and asynchronous communication, where instant responses are not required.

\subsection{Activity Over Time}

Figure 5 shows an example of how activities have been plotted over time. This has subsequently been reduced to a core timeline in order to streamline the comparison of multiple activities. Henceforth, all activity over time is presented as aggregated timelines (e.g. Figure 6) for clarity. This is based on the work of Anderson et al. (2009).

Figure 6 supports the previous findings i.e. activity is similar across contexts, although a wide range was again observed in the laboratory results. However, one difference was that the practice-based participant stopped searching after $60 \%$ of the situation, exclusively interpreting for $20 \%$ before returning to searching unlike the more co-evolutionary approach in the other contexts. The figures' key characterises the practice results with respect to the laboratory and intermediary contexts. For example, 'more than int' means that the result from practice was greater than the intermediary results but not greater than the laboratory maximum. 
Figure 5: Cumulative time as a percentage of the total situation time for information seeking as an example of the underlying data and the aggregation approach

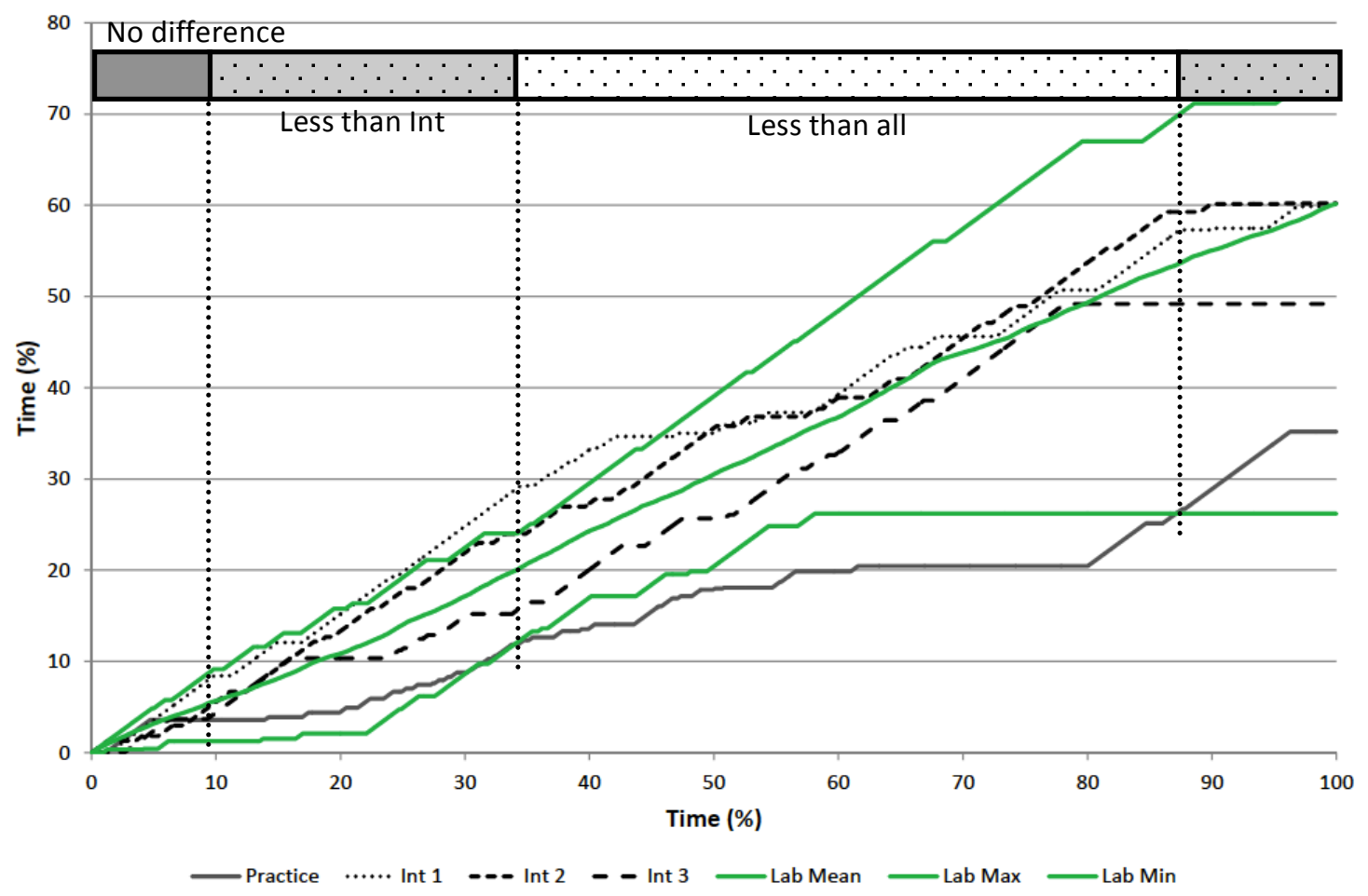

Figure 6: Aggregated timelines for the information seeking activities

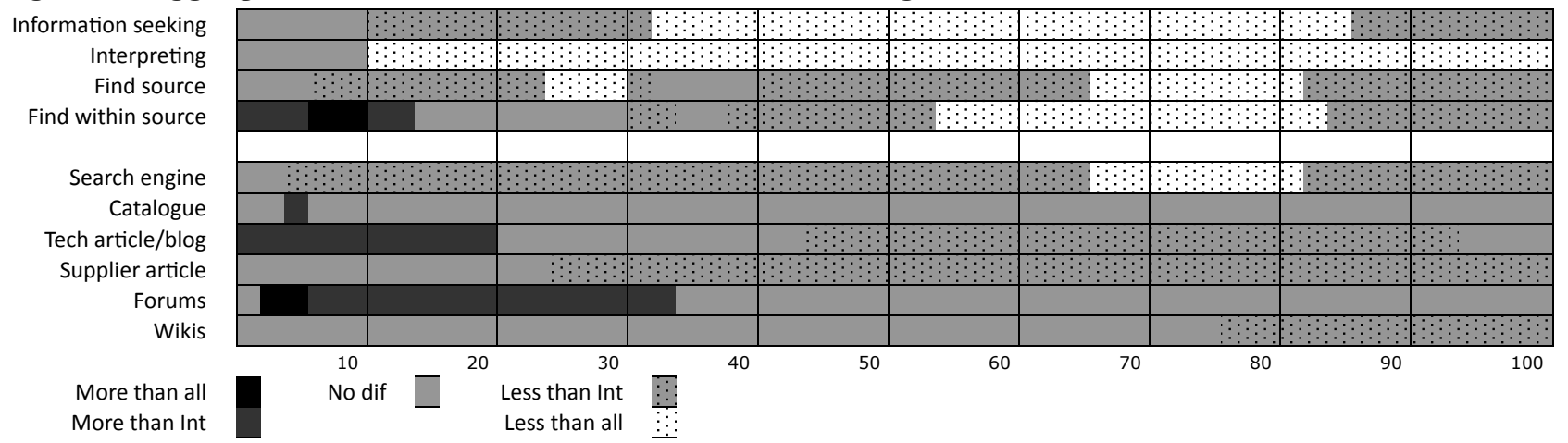

Figure 6 shows that at a high-level the intermediary and laboratory results are closely aligned, indicating little inherent difference due to the participant. However, the average difference between the laboratory mean and practice across these activities is $22 \%$. Further, Figure 6 gives an average difference between these contexts of just $10 \%$ for the specific searching activities. As such, it is unlikely that searching behaviour is dependant on setting, instead being linked to personal factors such as searching strategy or preference in sources. 


\subsection{Situation-specific Activity}

Table 6 shows that, although the laboratory mean is lower than in practice, the range in the laboratory context is similar to that seen in the intermediary.

Table 6: The number of searches and sources used by participants during the situation

\begin{tabular}{|l|l|l|}
\hline & Total number of searches & Total number of sources \\
\hline \hline Practice & 72 & 6 \\
\hline Intermediary 1 & 61 & 7 \\
\hline Intermediary 2 & 80 & 7 \\
\hline Intermediary 3 & 38 & 5 \\
\hline Laboratory mean & 47.8 & 5.6 \\
\hline
\end{tabular}

Here again, there is no clear trending or substantial separation between the contexts. The results show that all participants were aligned with practice, again suggesting that the individual is the key factor affecting searching activity. It is surprising that, although the practitioner participants were more experienced than the students, their searching activity did not differ substantially.

\section{Core Design Situation 2: Ideation}

This section explores the core design situation 'ideation' and follows the same format as Section 5.

\subsection{Focus of Activity}

Table 7 highlights two main differences between contexts. Firstly, the laboratory (56\% mean, $44 \%$ minimum) shows substantially more 'exploring' activity than the intermediary (38\%) or practice (38\%) results. Secondly, 'recognising need', 'informing' and 'confirming' are all substantially higher in the other contexts compared to practice.

Table 7: Differences in duration between contexts for selected activities

\begin{tabular}{|l|l|l|l|}
\hline \multirow{2}{*}{ Context } & \multicolumn{3}{|c|}{ Duration of coded activity (\%) } \\
\cline { 2 - 4 } & Recognising need & Informing & Confirming \\
\hline \hline Laboratory mean (Minimum) & $8(6)$ & $42(39)$ & $13(10)$ \\
\hline Intermediary & 9 & 36 & 13 \\
\hline Practice & 0 & 3 & 0 \\
\hline
\end{tabular}

Figure 7 highlights the lack of 'recognising need', 'requesting information', 'informing', 
'confirming' and also 'goal setting', which accounted for only $0.7 \%$ of instances compared to the laboratory (4\%) and intermediary (5\%). Further, Figure $7 \mathrm{~b}$ emphasises the conversational nature of the task, with $77 \%$ of the coded activities lasting less than 20 seconds.

Figure 7: a) Coded activity duration as a percentage of the total situation time, b) number of instances and c) mean time per instance

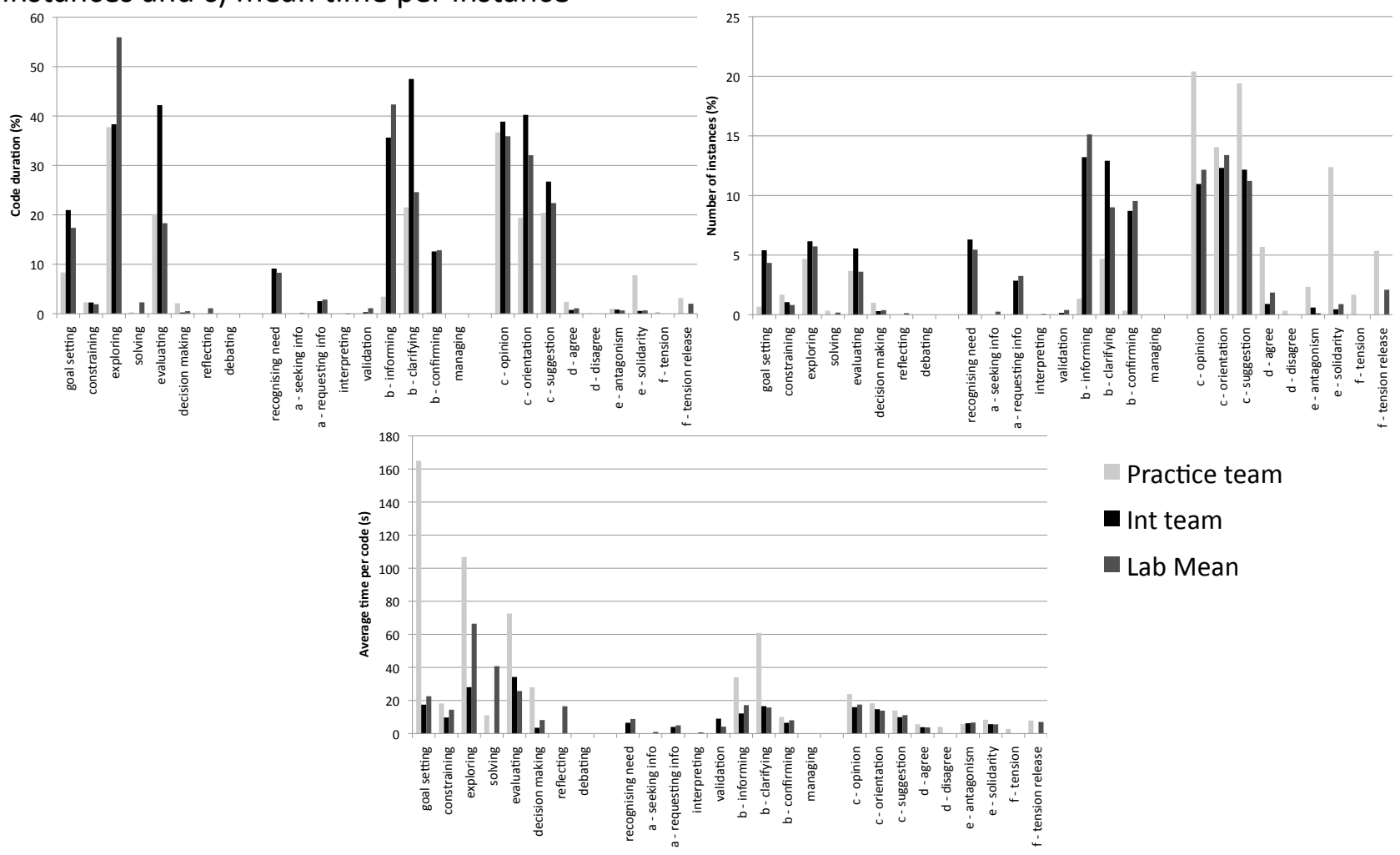

In contrast to the first core design situation, there were no clear trends apparent in terms of duration, total number of instances or average time per instance, except in two cases. Specifically the activities 'agree', 'antagonism', 'solidarity', 'tension' and 'tension release' had substantially less instances in the other contexts compared to practice. As the intermediary results closely aligned with those from the laboratory, it is unlikely that this difference was due to factors such as team history. It is, therefore, possible that this difference can be attributed to the more relaxed nature of the situation in practice. In the second case, the practice-based participants spent longer per instance on 'goal setting' with it constituting a single instance at the start of the situation. A possible explanation for this is that in practice the task goal was fixed and well established prior to the situations and, as such, little refinement or further discussion was necessary. This is in contrast 
to the other contexts where participants continued exploring possibilities throughout.

\subsection{Activity Over Time}

Figure 8 shows the activity over time and highlights the difference in 'goal setting' in the laboratory and intermediary contexts, which show a more linear trend in comparison to practice with a single event at the start of the situation.

Figure 8: Aggregated timelines for the different activities

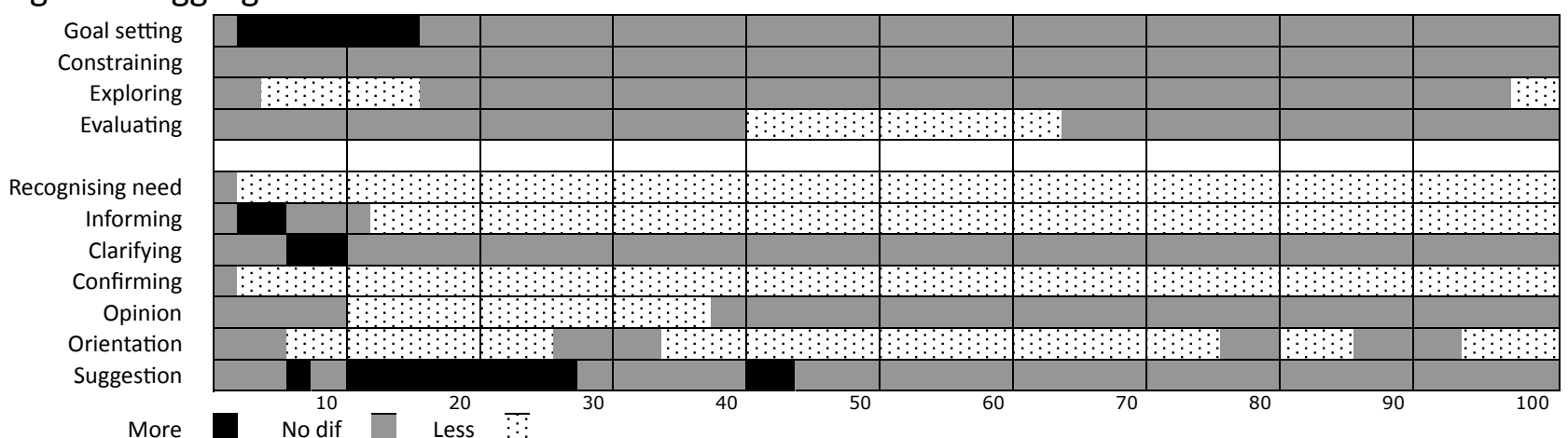

Further, the results for 'recognising need', 'informing' and 'clarifying' support the results for 'goal setting', with no 'recognising need' and a short 'informing'/'clarification' carried out at the start. However, despite these differences, the contexts show a similar conversational structure with 'opinion', 'orientation' and 'suggestion' closely aligned.

Table 8 gives the data for linear trend lines used to approximate the results from the three contexts in order to support this comparison. The fact that all $R^{2}$ values exceed 0.8 suggests that all three contexts can be approximated effectively using a linear trend, while the similarity in slope indicates that the contexts are comparable.

Table 8: Trend line data for conversation activities over time

\begin{tabular}{|l|l|l|l|}
\hline \multirow{2}{*}{ Context } & \multicolumn{3}{|c|}{ Duration of coded activity (slope/ $\mathbf{R}^{\mathbf{2}}$ ) } \\
\cline { 2 - 4 } & Opinion & Orientation & Suggestion \\
\hline \hline Laboratory mean & $0.37 / 0.99$ & $0.34 / 0.99$ & $0.23 / 0.99$ \\
\hline Intermediary & $0.35 / 0.98$ & $0.44 / 0.98$ & $0.27 / 0.99$ \\
\hline Practice & $0.36 / 0.92$ & $0.23 / 0.94$ & $0.25 / 0.85$ \\
\hline
\end{tabular}

The results for 'exploring' show a close correlation (practice $=5 \%$; intermediary $=6 \%$; laboratory 
mean $=6 \%$ (Figure 8$)$ ), suggesting that problem solving activity is similar across contexts despite the differences in leadership/goal setting. Other differences include the fact that 'recognising need', 'informing' and 'confirming' are not present in practice, which again supports the explanation developed in regard to 'goal setting'. In the case of practice, a clear team leader coupled with pre-established goals means that there was little clarification needed and 'informing' and 'recognising need' take place in a briefing at the start, or prior to the session. However, all other activities are closely correlated across contexts suggesting that the underlying mechanisms and the structure of the ideation discussions are fundamentally similar.

\subsection{Situation-specific Activity}

Exploring ideation specifically, Figure 9 shows the count of cumulative ideas generated over the course of the situation for each of the teams.

Figure 9: Ideas generated during the situation

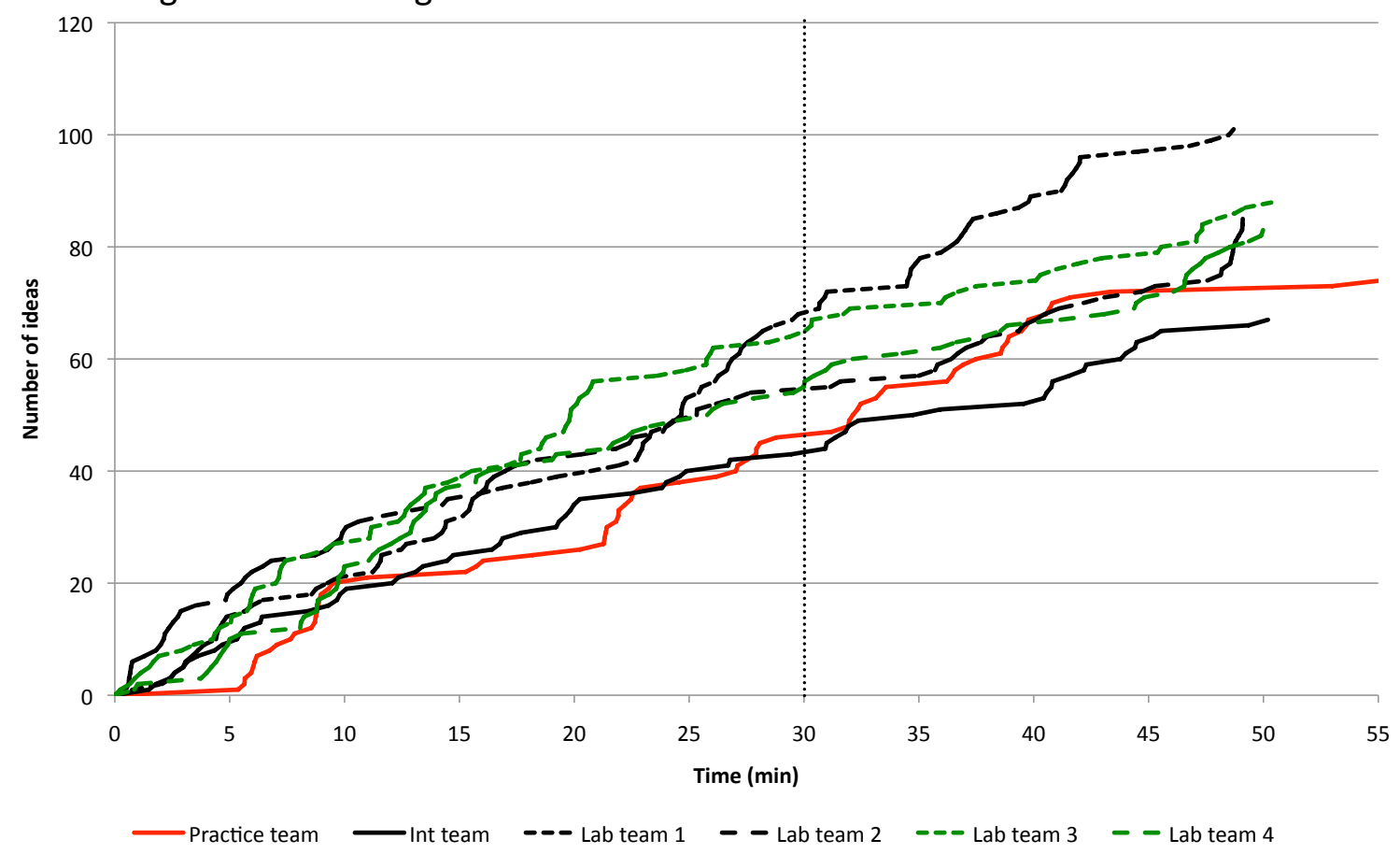

Table 9 further decomposes ideation with respect to the rate of idea generation - split into two periods ( $0-30$ minutes and $30-50$ minutes) based on Howard et al.'s (2010) work. The $\mathrm{R}^{2}$ values for linear approximations are closely related, with an average of 0.96 and a spread of only 0.04 
suggesting the various contexts share similar underlying structures and trends.

Table 9: Details of ideation for the three contexts and the laboratory teams

\begin{tabular}{|l|l|l|l|l|l|l|}
\hline & \multicolumn{2}{l|}{ Total number of ideas } & \multicolumn{2}{l|}{ Ideation rate (ideas per $\mathbf{m i n}$ ) } & \multicolumn{2}{l|}{$\mathbf{R}^{\mathbf{2}}$ value for linear trend line } \\
\cline { 2 - 7 } Time (min) & $0-30$ & $30-50$ & $0-30$ & $30-50$ & $0-30$ & $30-50$ \\
\hline \hline Lab 1 & 68 & 33 & 2.27 & 1.65 & 0.98 & 0.95 \\
\hline Lab 2 & 54 & 31 & 1.80 & 1.55 & 0.87 & 0.95 \\
\hline Lab 3 & 64 & 24 & 2.13 & 1.20 & 0.98 & 0.97 \\
\hline Lab 4 & 55 & 28 & 1.83 & 1.40 & 0.95 & 0.94 \\
\hline \hline Practice & 46 & 26 & 1.84 & 1.04 & 0.95 & 0.97 \\
\hline Int & 43 & 24 & 1.43 & 0.8 & 0.99 & 0.95 \\
\hline Lab Mean & 60 & 29 & 2.01 & 1.45 & 0.95 & 0.95 \\
\hline
\end{tabular}

Table 10 details the drop in ideation rate specifically.

Table 10: Change in ideation rate for the three contexts

\begin{tabular}{|l|l|l|}
\hline & Drop in ideation rate (ideas per min) & Drop in ideation rate (\% of initial rate) \\
\hline \hline Practice & 0.80 & 43 \\
\hline Intermediary & 0.63 & 44 \\
\hline Laboratory Mean & 0.56 & 28 \\
\hline
\end{tabular}

A comparison of the number of ideas generated over time coupled with an assessment of the ideation rate, shows that, although there is correlation across contexts, practitioners have a consistently lower total number of ideas and ideation rate (difference between the laboratory mean and practice $=17$ ideas and 0.3 ideas per minute). This again suggests that the underlying mechanisms driving idea generation are similar but that there are fundamental differences between practitioners and students. The similarity between the intermediary and practice contexts also supports the identification of the primary differentiating factor as the participant rather than the task or the setting.

\section{Core Design Situation 3: Review Meeting}

This section explores the core design situation 'review meeting' and follows the same format as Sections 5 and 6.

\subsection{Focus of Activity and Situation-specific Activity}

Figure 10 shows three substantial differences between laboratory and practice. Firstly, the 
duration of 'evaluating' in the laboratory (mean $=30 \%$, minimum $=13 \%$ ) is greater than in practice (11\%). Secondly, there is substantially less 'debate' and 'clarification' activity in the laboratory (maximum $=4 \%$ and $46 \%$ respectively) compared to practice ( $20 \%$ and $60 \%$ respectively). Finally, 'sketching' accounts for more time in the laboratory (70\% verses $6 \%$ in practice) and there are more instances of 'drawing' and 'communication' use in practice (3\% and 10\% respectively). These differences collectively suggest that activity in the laboratory is less diverse than in practice.

Further, Figure 10c shows that the average activity lasts 56 seconds longer in practice than in the other contexts. As the practice-based situation only included two participants, it is possible that this difference could be a product of team size. However, no such pattern is present in the conversational activities ('opinion' - 'tension release').

Figure 10: a) Coded activity duration as a percentage of the total situation time, b) number of instances and c) mean time per instance

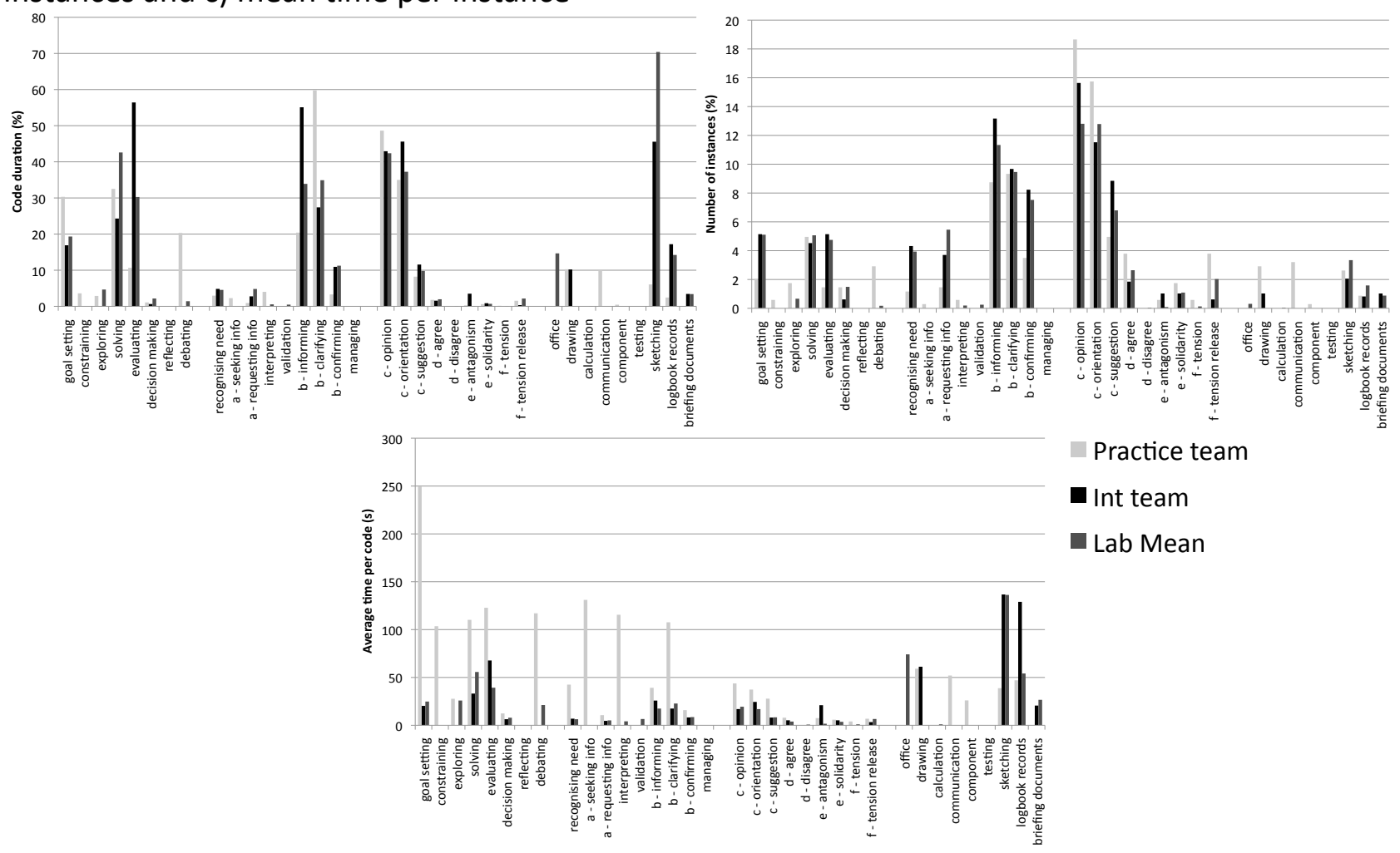

In terms of total duration and total number of instances several differences emerged: 'sketching' (more in the laboratory), 'debating (less in the laboratory) and range of artefact use (less in the laboratory), with less time given to the use of 'communications' and 'components' in the 
laboratory. These can be attributed to the embedded nature of practice within a pre-existing design process and the associated importance of asynchronous communication and prototyping. Finally, the laboratory consistently spends substantially less time per instance, although it is difficult to suggest an obvious reason for this trend.

\subsection{Activity Over Time}

Figure 11 again highlights the difference in the structure of 'goal setting' and 'evaluating' in the laboratory and intermediary contexts, which show a more linear trend in comparison to practice with a single event. These differences can be associated with the more focused nature of the laboratory and intermediary contexts compared to practice where multiple subtasks are undertaken and less focus is given to completing a single final design.

Figure 11: Aggregated timelines for the different activities

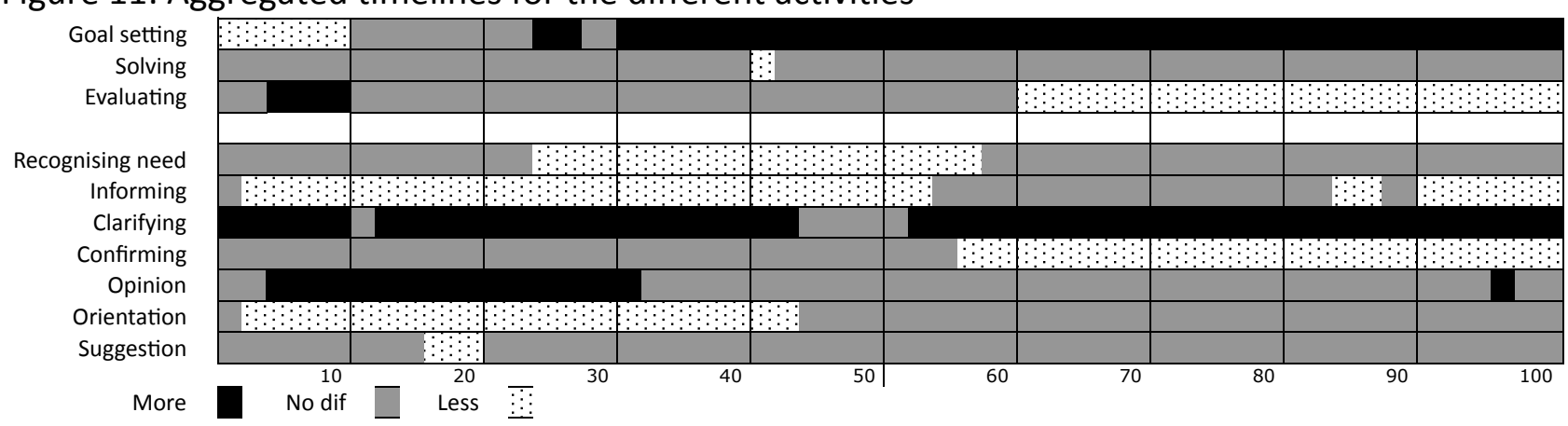

Figure 11 shows no other substantial differences except in the case of 'confirming' where the level of activity reduces after $50 \%$ of the situation. As the other activities do not show this attenuation, it suggests that the practice-based participants changed focus at this point. However, this does not affect the conversational aspects, which are closely related across the contexts as in Table 11.

Table 11: Trend line data for conversation activities over time

\begin{tabular}{|l|l|l|l|}
\hline \multirow{2}{*}{ Context } & \multicolumn{3}{|c|}{ Duration of coded activity (slope/ $\mathbf{R}^{2}$ ) } \\
\cline { 2 - 4 } & Opinion & Orientation & Suggestion \\
\hline \hline Laboratory mean & $0.45 / 0.99$ & $0.40 / 0.96$ & $0.11 / 0.97$ \\
\hline Intermediary & $0.37 / 0.92$ & $0.53 / 0.89$ & $0.10 / 0.89$ \\
\hline Practice & $0.49 / 0.99$ & $0.34 / 0.98$ & $0.10 / 0.86$ \\
\hline
\end{tabular}

Based on these results two key areas are highlighted. Firstly, 'goal setting' plays a less substantial 
role in the laboratory while solving activity is tightly clustered across contexts with a range of $18 \%$ excluding an outlier at $63 \%$ (20\% greater than the next highest result). Secondly, 'evaluating' shows substantially more spread compared to the other coded activities with a final range of $45 \%$. In this case, practice also shows a different structure to that observed in the laboratory or intermediary contexts. This suggests that although fundamental problem solving/evaluation is similar across contexts, 'goal setting' plays a different role in the laboratory. This can again be attributed to the fact that the practice-based situation is embedded within the wider design process and therefore plays an important shaping role not present in the laboratory or intermediary context. This is further supported by Figure 11, which shows no substantial differences in conversational activities across contexts.

\section{Characterising Relationships Between the Laboratory and Practice}

The relationships for each of the three core design situations are key to the comparison and are dealt with in the next section. Each subsection presents the main findings for that situation, discusses their validity and summarises the overall results.

\subsection{Information Seeking}

Finding 1: Participants in the laboratory spend more time (as a percentage of the situation and in comparison to practice) on information seeking activity (seeking, interpreting and the individual sources) due to the narrower scope of activities undertaken. It is to be noted that although these differences are not individually substantial the fact that there is a consistent trend across all the activities is.

Finding 2: There are substantially less information requests and other asynchronous, longitudinal activities in the laboratory due to differences in how integrated the participants are with the wider design process. The practice-based participants spent $1.6 \%$ of their activities and 
$5 \%$ of their time requesting information via, for example, supplier contact forms. This leads to an embedded scenario where information seeking generates requests, which will be fulfilled at a later time, not necessarily during the same information seeking activity. In the case of the other contexts the request had to be fulfilled within the design session.

Finding 3: Little difference in searching behaviour is observed for the different contexts. That is, the laboratory mean was close to the observed results in practice. This includes 'number of searches', 'number of sources', 'finding source' and 'finding within source'. The variation is more attributable to individual factors as there are no trends across contexts.

\subsubsection{Validation}

Three key studies (King, et al., 1994; Puttre, 1991; M. A. Robinson, 2010) highlight the variability in searching behaviour and the wide scope of activities undertaken by practitioners, suggesting that laboratory participants are more focused in their information activities supporting Finding 1.

With respect to Finding 2, the work of Robinson (2010) supports the embedded nature of practice e.g. approximately $9 \%$ of practitioners' time is spent seeking information from other people. This, as well as the embedded nature of activities within the design process, supports the second finding that there are substantially more information requests and other asynchronous or longitudinal activities due to the embedded nature of practice in comparison to other contexts (Hales, 1991).

Finally, in order to validate Finding 3 , it is necessary to consider the information sources and confirm the primacy of Internet based searching. Allard et al. (2009) highlight Internet based information as the primary seeking 'information activity'. Further, the work of Keller et al. (2007) supports the characterisation of many of the observed Internet activities, highlighting the importance and complexity of information seeking or 'information gathering' tasks in the context of computer science students. This is further supported by Holscher and Strube (2000) who 
emphasize the interplay between browsing and search engine activities - linking to the results for 'finding source' and 'finding within source'.

\subsubsection{Summary}

In summary, although direct validation is not possible, the identified sources correlate with the findings. Table 12 summarises and highlights areas of difference between laboratory and practice; with respect to practice, i.e. 'more' represents, for example, a longer duration in the laboratory. Differences have been described as substantial if they fall outside the interpersonal variation seen in the laboratory. Areas where substantial differences are present are shaded for clarity (see key).

\begin{tabular}{|l|l|l|l|l|}
\hline Key: & Less than practice & No substantial difference & More than practice & Not applicable (N.A.) \\
\hline
\end{tabular}

Table 12: Differences between contexts by activity

\begin{tabular}{|l|l|l|l|l|l|}
\hline \multirow{2}{*}{ Code } & \multicolumn{5}{|c|}{ Focus of analysis } \\
\cline { 2 - 6 } & Duration & Instances & $\begin{array}{l}\text { Time per } \\
\text { instance }\end{array}$ & Activity over time & $\begin{array}{l}\text { Situation } \\
\text { specific }\end{array}$ \\
\hline \hline Seeking information & no sub. dif. & no sub. dif. & no sub. dif. & dif. structure & no sub. dif. \\
\hline $\begin{array}{l}\text { Requesting } \\
\text { information }\end{array}$ & less & less & less & N.A. & N.A. \\
\hline Interpreting & more & more & no sub. dif. & dif. structure & N.A. \\
\hline \hline Search engine & no sub. dif. & no sub. dif. & no sub. dif. & no sub. dif. & N.A. \\
\hline Catalogue & no sub. dif. & no sub. dif. & no sub. dif. & no sub. dif. & N.A. \\
\hline $\begin{array}{l}\text { Technology } \\
\text { article/blog }\end{array}$ & no sub. dif. & no sub. dif. & no sub. dif. & no sub. dif. & N.A. \\
\hline Supplier article & no sub. dif. & no sub. dif. & no sub. dif. & no sub. dif. & N.A. \\
\hline Forums & no sub. dif. & no sub. dif. & no sub. dif. & no sub. dif. & N.A. \\
\hline Expert/supplier & less & less & less & N.A. & N.A. \\
\hline Social media & no sub. dif. & no sub. dif. & no sub. dif. & N.A. & N.A. \\
\hline Wiki & no sub. dif. & no sub. dif. & no sub. dif. & no sub. dif. & N.A. \\
\hline Patent & no sub. dif. & no sub. dif. & no sub. dif. & N.A. & N.A. \\
\hline Standard & no sub. dif. & no sub. dif. & no sub. dif. & N.A. & N.A. \\
\hline \hline Finding source & no sub. dif. & no sub. dif. & no sub. dif. & N.A. & N.A. \\
\hline $\begin{array}{l}\text { Finding within } \\
\text { source }\end{array}$ & no sub. dif. & no sub. dif. & no sub. dif. & N.A. & N.A. \\
\hline
\end{tabular}

\subsection{Ideation}

Finding 4: Goal setting activities (recognising need, informing and confirming) take the form of a discreet briefing in practice and account for substantially more of the situation in the laboratory, due to differences in embeddedness. In this case these activities are only present during the first $10 \%$ of the situation in practice, suggesting that much of this activity had already taken place 
during prior work. In contrast, for the laboratory and intermediate contexts these activities collectively represent $64 \%$ and $57 \%$ of the total duration respectively.

Finding 5: There is little difference across contexts in terms of the problem solving (constraining, exploring and evaluating) and conversational activities (opinion, orientation and suggestion). All of these activities show no substantial differences over time when compared to the other contexts.

Finding 6: Ideation activity is similar across contexts with the difference in the number and rate of ideas generated due to the level of experience of the participant rather than the task or the setting. Linearity of the curve and $R^{2}$ values show no substantial differences across contexts $\left(R^{2}\right.$ range $=0.04$, mean $=0.96)$ while there are differences in magnitude, with practitioners producing fewer ideas irrespective of context (average difference from laboratory mean $=15$ less ideas in minutes 0-30 and 4 less in minutes 30-50).

\subsubsection{Validation}

From the work of Howard et al. (2010), two teams can be identified that provide possible sources of validation with both teams completing 50 minutes of uninterrupted brainstorming. These teams were larger than those examined in this work ( 9 and 6 members) and were recorded in practice. Figure 12 shows the results for Howard et al.'s teams as well as the findings for this study. 
Figure 12: Validating ideation against Howard et al. (2010)

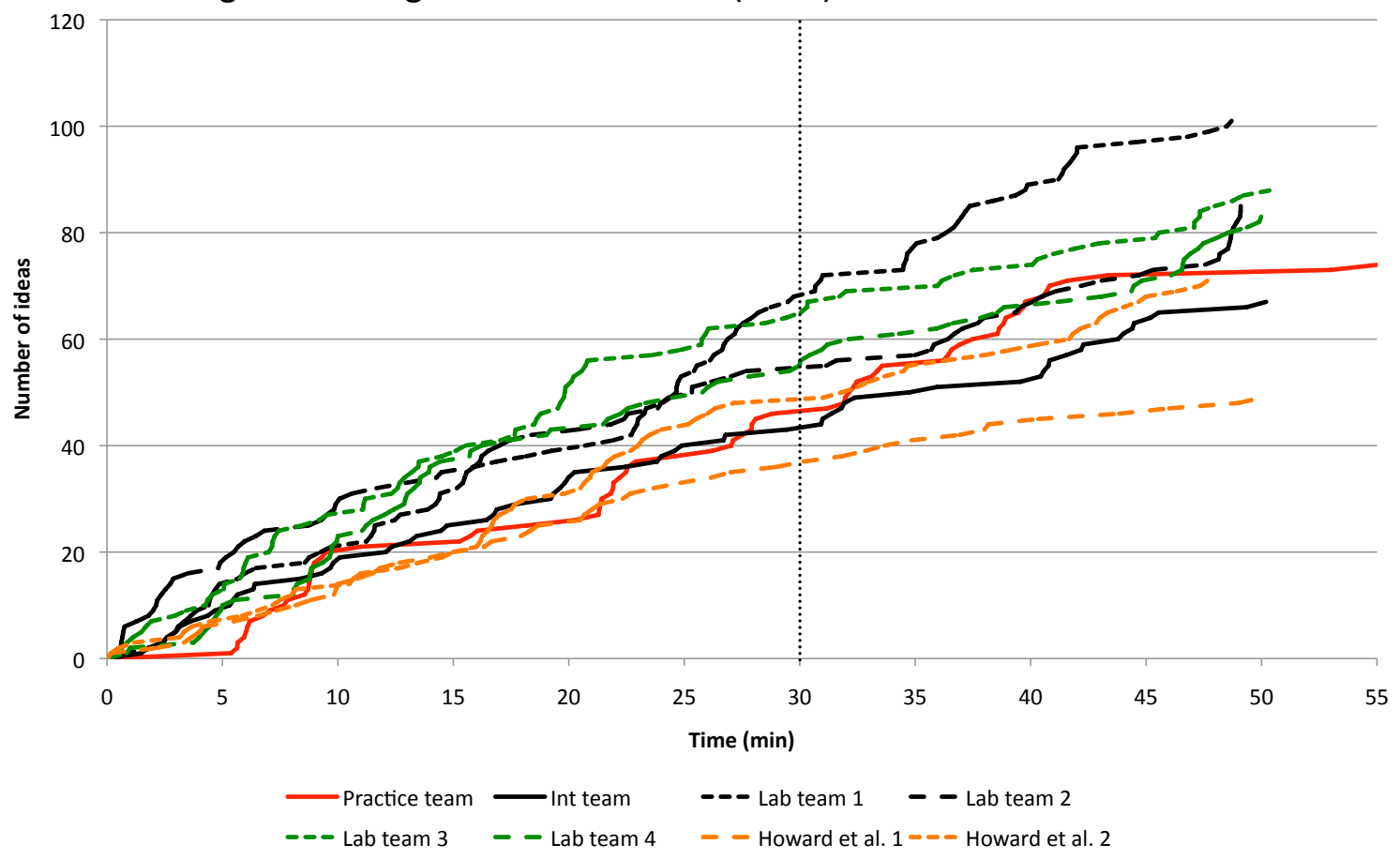

Figure 12 shows that, although there is some variation amongst the results, Howard et al.'s (2010) teams supporting the initial findings. Further, the studies using student participants are tightly clustered and consistently higher than the equally tightly clustered results for the practitioner participants as highlighted in Table 13.

Table 13: Maximum v. Minimum, difference in number of ideas generated over time

\begin{tabular}{|l|l|l|}
\hline & \multicolumn{2}{|l|}{ Difference (max. - min.) in number of ideas } \\
\hline Time (minutes) & $0-30$ & $30-50$ \\
\hline \hline Laboratory & 13 & 9 \\
\hline Practice (incl. intermediary and Howard et al.'s teams) & 12 & 13 \\
\hline
\end{tabular}

This further supports the finding that practitioners consistently produce fewer ideas irrespective of other factors (including group size) and that practice is representative of other independent studies of practitioners. The fact that the teams perform consistently also supports the finding that underlying ideation activity is similar across contexts and is not substantially affected by differences in goal setting behaviour.

Table 14 reinforces the results outlined in Figure 12 and again shows the laboratory studies to be consistently higher in terms of ideation rate. The drop in rate is less substantial in Howard et al.'s (2010) teams, however, the data supports the overall findings summarised in this section. 
Table 14: Validating changes in ideation rate against Howard et al. (2010)

\begin{tabular}{|l|l|l|l|l|}
\hline & \multicolumn{2}{|l|}{ Ideation rate (ideas per min) } & \multicolumn{2}{l|}{ Drop in ideation rate } \\
\hline Time (min) & $0-30$ & $30-50$ & Ideas per minute & $\%$ of initial rate \\
\hline \hline Practice & 1.84 & 1.04 & 0.80 & 43 \\
\hline Intermediary & 1.43 & 0.8 & 0.63 & 44 \\
\hline Laboratory Mean & 2.01 & 1.45 & 0.56 & 28 \\
\hline Howard et al. team 1 & 1.60 & 1.15 & 0.45 & 28 \\
\hline Howard et al. team 2 & 1.20 & 0.8 & 0.40 & 33 \\
\hline
\end{tabular}

The findings are further supported by the extant literature (Cross, 2004; Judith \& Herbert, 2007).

Atman et al. (1999) attribute lower idea production in experts to the more efficient nature of the experienced design process. It is argued that experienced designers are more capable of parallel thinking (Seitamaa-Hakkarainen \& Hakkarainen, 2001) and have more structured cognitive processes (Kavakli \& Gero, 2002). Due to these skills, less iteration is needed to achieve an acceptable result, in contrast to the novices typical 'trial and error' approach (Ahmed, et al., 2003).

Finally, this is also supported by the recent work of Snider et al. (2013) who highlight the important role personal factors play in determining creative design approach.

\subsubsection{Summary}

In summary, both direct (via Howard et al. (2010)) and indirect (via literature) validation confirms the key findings for this study. Table 15, highlights areas of difference between laboratory and practice using the same approach as outlined in Section 8.1.2.

Table 15: Differences between contexts by activity

\begin{tabular}{|l|l|l|l|l|l|}
\hline \multirow{2}{*}{ Code } & \multicolumn{5}{|c|}{ Focus of analysis } \\
\cline { 2 - 6 } & Duration & Instances & $\begin{array}{l}\text { Time per } \\
\text { instance }\end{array}$ & $\begin{array}{l}\text { Activity over } \\
\text { time }\end{array}$ & Situation specific \\
\hline \hline Goal setting & no sub. dif. & more & less & dif. structure & N.A. \\
\hline Constraining & no sub. dif. & no sub. dif. & no sub. dif. & no sub. dif. & N.A. \\
\hline Exploring & more & no sub. dif. & no sub. dif. & no sub. dif. & N.A. \\
\hline Solving & no sub. dif. & no sub. dif. & no sub. dif. & N.A. & N.A. \\
\hline Evaluating & no sub. dif. & no sub. dif. & less & no sub. dif. & N.A. \\
\hline Decision making & less & less & less & N.A. & N.A. \\
\hline Reflecting & no sub. dif. & no sub. dif. & no sub. dif. & N.A. & N.A. \\
\hline Debating & no sub. dif. & no sub. dif. & no sub. dif. & N.A. & N.A. \\
\hline \hline Recognising need & more & more & more & dif. structure & N.A. \\
\hline Seeking information & no sub. dif. & no sub. dif. & no sub. dif. & N.A. & N.A. \\
\hline $\begin{array}{l}\text { Requesting } \\
\text { information }\end{array}$ & more & more & more & N.A. & N.A. \\
\hline Interpreting & no sub. dif. & no sub. dif. & no sub. dif. & N.A. & N.A. \\
\hline
\end{tabular}




\begin{tabular}{|l|l|l|l|l|l|}
\hline Validation & no sub. dif. & no sub. dif. & no sub. dif. & N.A. & N.A. \\
\hline Informing & more & more & less & dif. structure & N.A. \\
\hline Clarifying & no sub. dif. & more & less & no sub. dif. & N.A. \\
\hline Confirming & more & more & no sub. dif. & dif. structure & N.A. \\
\hline \hline Opinion & no sub. dif. & less & less & no sub. dif. & N.A. \\
\hline Orientation & no sub. dif. & no sub. dif. & less & no sub. dif. & N.A. \\
\hline Suggesting & no sub. dif. & less & no sub. dif. & no sub. dif. & N.A. \\
\hline Agree & no sub. dif. & less & less & N.A. & N.A. \\
\hline Disagree & no sub. dif. & no sub. dif. & less & N.A. & N.A. \\
\hline Antagonism & no sub. dif. & less & no sub. dif. & N.A. & N.A. \\
\hline Solidarity & less & less & less & N.A. & N.A. \\
\hline Tension & no sub. dif. & less & less & N.A. & N.A. \\
\hline Tension release & no sub. dif. & less & no sub. dif. & N.A. & N.A. \\
\hline \hline Ideas & N.A. & more & N.A. & more & lower drop in rate \\
\hline
\end{tabular}

\subsection{Design Review}

Finding 7: Sketching plays a larger role in the intermediary and laboratory contexts in comparison to practice. Specifically, sketching activity accounts for $64 \%$ more time in the laboratory with each instance of sketching lasting on average 97 seconds longer.

Finding 8: Goal setting activity is substantially lower and has a more linear structure in the other contexts in comparison to practice, where $45 \%$ of all goal setting occurred during a single instance. In this case both goal setting and clarifying account for substantially less time in the laboratory ( $11 \%$ and $30 \%$ less than practice respectively). In addition goal setting effectively ceases after $60 \%$ of the situation in practice in contrast to the other contexts.

Finding 9: Problem solving (solving and recognising need) and conversational activity (opinion, orientation and suggestion) show no substantial differences across contexts. This is despite differences in evaluating activity, which accounts for $19 \%$ more time in the laboratory and effectively ceases after $10 \%$ of the situation in practice.

\subsubsection{Validation}

The role of sketching in each of the three contexts was primarily in design development - being used to expand on various concepts and ideas. However, a key driver in the laboratory and intermediary studies was the production of a final concept suggesting that sketching is task rather 
than participant dependent. This is supported by several sources. Perry and Sanderson (1998) and Huet et al. (2009) highlight the fact that sketching is one part of a more complex design activity suggesting a link to task. Further, Song and Agogino (2004) also emphasised the task dependency of sketching. As such, it is possible to conclude that sketching activity is primarily task-dependent and, therefore, accounts for more time in the laboratory due to the more limited nature of the tasks undertaken. However, the similarity of the other codes related to sketching activity particularly 'clarifying' and 'informing' - suggest that the fundamental use of sketching for specific tasks is similar across contexts.

Secondly, 'goal setting' in practice accounted for an average of $11 \%$ more of the situation and took the form of a series of discreet events compared to the other contexts where it could be modelled as linearly distributed throughout the situation $\left(R^{2}=0.91\right.$ (laboratory) and 0.90 (intermediary)). Again the differences between contexts can be attributed to the embeddedness of a situation within the design process, the need to set tasks and identify goals for further work is less dominant in the other contexts compared to practice. Although this finding is in itself not surprising it is important to highlight that it confirms the expectation that this activity is substantially different across contexts while also serves to highlight that despite this the other activities considered remain relatively similar.

Finally, the work of Huet et al. (2007) supports the finding that there is little fundamental difference in the activity of students and practitioners during a comparable design review situation. Huet et al. state that a design review involving graduate students was 'considered comparable to industry practices' as assessed by a group of industrial experts, supported by the correlation between the intermediary and laboratory contexts and implying that variation in activity is not primarily due to participant. 


\subsubsection{Summary}

In summary, all the identified sources correlate with the findings outlined in this section with no major contradictions. Table 16, again, highlights areas of difference between laboratory and practice using the same approach as outlined in Section 8.1.2.

Table 16: Differences between contexts by activity

\begin{tabular}{|c|c|c|c|c|}
\hline \multirow[t]{2}{*}{ Code } & \multicolumn{4}{|c|}{ Focus of analysis } \\
\hline & Duration & Instances & Time per instance & Activity over time \\
\hline Goal setting & less & more & less & dif. structure \\
\hline Constraining & less & less & less & N.A. \\
\hline Exploring & no sub. dif. & no sub. dif. & no sub. dif. & N.A. \\
\hline Solving & no sub. dif. & no sub. dif. & less & no sub. dif. \\
\hline Evaluating & more & no sub. dif. & less & dif. structure \\
\hline Decision making & no sub. dif. & no sub. dif. & less & N.A. \\
\hline Reflecting & no sub. dif. & no sub. dif. & no sub. dif. & N.A. \\
\hline Debating & less & less & less & N.A. \\
\hline Recognising need & no sub. dif. & more & less & no sub. dif. \\
\hline Seeking information & less & no sub. dif. & less & N.A. \\
\hline Requesting information & more & more & less & N.A. \\
\hline Interpreting & less & no sub. dif. & less & N.A. \\
\hline Validation & no sub. dif. & no sub. dif. & more & N.A. \\
\hline Informing & more & no sub. dif. & less & no sub. dif. \\
\hline Clarifying & less & no sub. dif. & less & less \\
\hline Confirming & more & more & less & dif. structure \\
\hline Opinion & no sub. dif. & less & less & no sub. dif. \\
\hline Orientation & no sub. dif. & no sub. dif. & less & no sub. dif. \\
\hline Suggesting & no sub. dif. & no sub. dif. & less & no sub. dif. \\
\hline Agree & no sub. dif. & no sub. dif. & less & N.A. \\
\hline Disagree & no sub. dif. & no sub. dif. & no sub. dif. & N.A. \\
\hline Antagonism & no sub. dif. & less & less & N.A. \\
\hline Solidarity & no sub. dif. & no sub. dif. & less & N.A. \\
\hline Tension & no sub. dif. & no sub. dif. & no sub. dif. & N.A. \\
\hline Tension release & no sub. dif. & no sub. dif. & less & N.A. \\
\hline Office & no sub. dif. & no sub. dif. & no sub. dif. & N.A. \\
\hline Drawing & less & less & less & N.A. \\
\hline Calculation & no sub. dif. & no sub. dif. & no sub. dif. & N.A. \\
\hline Communication & less & less & less & N.A. \\
\hline Component & less & no sub. dif. & less & N.A. \\
\hline Testing & no sub. dif. & no sub. dif. & no sub. dif. & N.A. \\
\hline Sketching & more & no sub. dif. & more & N.A. \\
\hline Logbook record & more & no sub. dif. & no sub. dif. & N.A. \\
\hline Briefing documents & more & more & more & N.A. \\
\hline
\end{tabular}

\section{Limitations}

The main limitation of this study is the sample size, which has three aspects: the sample of practice, significance of experimental studies and the situations considered. In order to ascertain 
the generalisability of the practice-based study a wider range of companies and practitioners need to be considered. Although an analysis of a significant number of companies and practitioners would undoubtedly address this, it is outside the scope of this paper. As such, this work can be seen as extending and testing existing comparative work by adopting a context focus and using a mixed methods approach (Ahmed, et al., 2003; Kavakli \& Gero, 2002; Seitamaa-Hakkarainen \& Hakkarainen, 2001). The small size of the student sample was considered sufficient due to the exploratory nature of the study outlined here. An extension of this work would be investing each of the identified findings with a specific study in order to statistically validate the findings using a larger population. Finally, a limited range of core situations was selected because the identification of differences in these situations was likely to have the greatest impact on current research. This focused the study on those subjects most commonly studied via laboratory experiments in design research at the cost of identify overarching differences affecting all design situations.

The second possible limitation was the variation between contexts e.g. linking the three situations to form a coherent task for the laboratory study or the selection of the student and practitioner populations. However, this was a key aspect of the study and contributes to its relevance for design researchers. In particular, students were used as they form the most common experimental participants - thus better representing the conditions typical of laboratory studies in design research. Similarly, the practitioners were used despite not having expert levels of experience because they formed a representative sample of the company's population and, as such, are more representative of those practitioners typically used in design research studies. As stated in the introduction, the aim of this paper has not been to compare experts to novices but instead compare laboratory to practice - as such, those populations most representative of each context have been used. This subsequently supports a more general validation of laboratory-based studies in design research as well as the generalisability of this study in particular. 
Thirdly, the three-stages (practice, laboratory and intermediary) are resource intensive, limiting the scope of its application. However, they demonstrate the efficacy of using a mixed methods approach in design research, allowing for the combination of multiple studies carried out in varied contexts where variables can be identified and isolated. As such, despite pragmatic considerations, the potential for the expansion and refinement of this approach to include multiple situations and contexts offers significant opportunities for future qualitative and quantitative analyses.

A final issue requiring further examination is the period of acclimatization. This was based on a conservative estimate obtained from a review of relevant literature. An improvement would be to carry out studies to explicitly determine the extent of the disruption, the time required for participants to return to normal practice and the level of any lingering effects. In this case the acclimatization period was considered sufficient as evidenced by participant's checking private emails, using online banking and other personal activities.

\section{Conclusions}

A range of findings have been highlighted in Section 8, three core conclusions can be synthesised from these and the wider pattern of results:

(1) The core design activity in each situation shows little difference across contexts or population - supported by findings 3,5 and 9 .

(2) Contextual factors play a key role, particularly in terms of embeddedness. However, their impact appears to be limited to a number of logically identifiable variables - supported by findings 2,4 and 8 .

(3) Experiential/demographic differences are important but conform with and support existing work on design activity - supported by findings 1,6 and 7 . 
Although the scope of this study has been limited by population size it has been specifically designed to address the other main factors affecting the generalisability of studies of this type. The given tasks have been based on an observational study of industry ensuring their relevance as 'realistic' tasks - with the inherent limitation that the stakes are significantly lower in an experimental study. The populations have been selected based on those typically studied in design research and therefore give a good basis for applying these findings across the field. Finally, the fact that numerous measures of design activity for a variety of situations show similar trends suggests that this work is indicative of wider truths as emphasised in the conclusions above. That these conclusions support existing work, logically fit with design theory and build on multifaceted evidence implies that applicability within the context of the studied situations is relatively robust. However, it is impossible to overstate the complexity of the overall design process and, as such, further work is required to identify the fundamental mechanisms underpinning the identified trends, findings and conclusions before more reliable general application of these findings will be possible in other contexts.

Based on these factors this study has a number of implications for design researchers. First, the conclusions support much of the extant comparative work carried in the field, while also identifying a number of new factors to be investigated. Second, they demonstrate the limited effect of study context. In this case all contextual effects could be linked to existing design research logic and, as such, more easily isolated from the experimental variables. Third, results from laboratory studies can give genuine insight into design practice although with a limited level of accuracy depending on variable and context. Specifically, for the majority of activity variables considered the student population was so diverse that it encompassed the full range of practitioner activity (although some groupings and trends were evident even in this limited population). Finally, the study highlights the efficacy of using the three-part approach to give improved multifaceted insight into design situations. 
Ultimately, further work is needed to more fully explore the range of activities where substantial differences have not been observed in order to identify more subtle variables or factors that might affect design activity at a micro level. This would also allow for the identification of further contextual and demographic vectors affecting design activity, which may not have been evident in this study due to the limitations of population or considered variables. Ultimately, an expansion of this work, or an aggregation of more focused studies, to allow for a statistically significant sample to be considered would be the logical next step in any further comparative work wishing to characterise and differentiate specific trends.

\section{Acknowledgements}

The work reported in this paper has been undertaken as part of the EPSRC Innovative Manufacturing Research Centre at the University of Bath (grant reference GR/R67507/0) and has been supported by a number of industrial companies. The authors gratefully acknowledge this support and express their thanks for the advice and support of all concerned. The authors would also like to thank Dr. Tom Howard for the provision of data. Finally, the authors would like to express their gratitude to the reviewers for their input.

\section{References}

Adair, J. G. (1984). The Hawthorne effect: A reconsideration of the methodological artifact. Journal of applied psychology, 69, 334-345.

Ahmed, S., Wallace, K. M., \& Blessing, L. (2003). Understanding the differences between how novice and experienced designers approach design tasks. Research in Engineering Design, 14, 1-11.

Allard, S., Levine, K. J., \& Tenopir, C. (2009). Design engineers and technical professionals at work: Observing information usage in the workplace. Journal of the American Society for Information Science and Technology, 60, 443-454.

Anderson, K., Nafus, D., Rattenbury, T., \& Aipperspach, R. (2009). Numbers Have Qualities Too: Experiences with Ethnomining. In Ethnographic Praxis in Industry Conference Proceedings (Vol. 2009, pp. 123-140): Wiley Online Library.

Atman, C. J., Chimka, J. R., Bursic, K. M., \& Nachtmann, H. L. (1999). A comparison of freshman and senior engineering design processes. Design Studies, 20, 131-152.

Badke-Schaub, P., \& Frankenberger, E. (1999). Analysis of design projects. Design Studies, 20, 465-480.

Ball, L. J., \& Ormerod, T. C. (2000). Putting ethnography to work: The case for a cognitive ethnography of design. International Journal of Human-Computer Studies, 53, 147-168.

Bolton, G. E., \& Ockenfels, A. (2008). Does laboratory trading mirror behaviour in real world markets?: Fair bargaining and competitive bidding on EBay: CESifo. 
Bonetti, D., Johnston, M., Clarkson, J. E., Grimshaw, J., Pitts, N. B., Eccles, M., Steen, N., Thomas, R., Maclennan, G., \& Glidewell, L. (2010). Research article applying psychological theories to evidence-based clinical practice: Identifying factors predictive of placing preventive fissure sealants. behaviour, 16, 18-23.

Button, G. (2000). The ethnographic tradition and design. Design Studies, 21, 319-332.

Cash, P., Elias, E. W. A., Dekoninck, E., \& Culley, S. J. (2011). Methodological insights from a rigorous small scale design experiment. Design Studies, 33, 208-235.

Cash, P., Hicks, B. J., \& Culley, S. J. (2010). An information requirement strategy for capturing and analysing design activity and behaviour. In Design 2010 International Design Conference. Dubrovnik, Croatia.

Cash, P., Hicks, B. J., Culley, S. J., \& Salustri, F. (2011). Designer behaviour and activity: An industrial observation method. In ICED 11 International Conference on Engineering Design. Copenhagen, Denmark.

Cook, T. D., Campbell, D. T., \& Peracchio, L. (1979). Quasi-experimentation. Palo Alto, CA, US: Consulting Psychologists Press.

Corremans, J. A. M. (2009). Measuring the effectiveness of a design method to generate form alternatives: an experiment performed with freshmen students product development. Journal of Engineering Design, 22, 259-274.

Cross, N. (2004). Expertise in design: An overview. Design Studies, 25, 427.

Edmonds, E. A., Weakley, A., Candy, L., Fell, M., Knott, R., \& Pauletto, S. (2005). The studio as laboratory: Combining creative practice and digital technology research. International Journal of Human-Computer Studies, 63, 452-481.

Eifert, G. H., Forsyth, J. P., Zvolensky, M. J., \& Lejuez, C. W. (1999). Moving from the laboratory to the real world and back again: Increasing the relevance of laboratory examinations of anxiety sensitivity. Behavior therapy, 30, 273-283.

Eisenhardt, K. M., \& Graebner, M. E. (2007). Theory building from cases: Opportunities and challenges. Academy of Management Journal, 50, 25-32.

Friedman, K. (2000). Creating design knowledge: From research into practice. In IDATER 2000 Conference. Loughborough, UK: Loughborough University.

Hagedorn, J., Hailpern, J., \& Karahalios, K. G. (2008). VCode and VData: illustrating a new framework for supporting the video annotation workflow. In Conference on Advanced Visual Interfaces (pp. 317-321). New York, USA: ACM.

Hales, C. (1991). Analysis of the engineering design process in an industrial context. Cambridge UK: Department of Engineering, University of Cambridge.

Holscher, C., \& Strube, G. (2000). Web search behavior of Internet experts and newbies. Computer networks, 33, 337-346.

Howard, T. J., Culley, S. J., \& Dekoninck, E. (2010). Reuse of ideas and concepts for creative stimuli in engineering design. Journal of Engineering Design, 0, 1-17.

Huet, G., Culley, S. J., McMahon, C., \& Fortin, C. (2007). Making sense of engineering design review activities. Artificial Intelligence for Engineering Design, Analysis and Manufacturing : AI EDAM, 21, 243-266.

Huet, G., McAlpine, H., Camarero, R., Culley, S. J., Leblanc, T., \& Fortin, C. (2009). The management of digital sketches through PLM solutions. In ICED 09 International Conference on Engineering Design. Stanford University, Stanford, CA, USA.

Judith, J., \& Herbert, B. (2007). Imparting design methods with the strategies of experts. In ICED 07 International Conference on Engineering Design (pp. 269-270). Paris, France.

Kavakli, M., \& Gero, J. S. (2002). The structure of concurrent cognitive actions: A case study on novice and expert designers. Design Studies, 23, 25-40.

Kellar, M., Watters, C., \& Shepherd, M. (2007). A field study characterising Web-based information-seeking tasks. Journal of the American Society for Information Science and Technology, 58, 999-1018. 
King, D. W., Casto, J., \& Jones, H. (1994). Communication by engineers: a literature review of engineers' information needs, seeking processes, and use. Washington, DC: Council on Library Resources

Leonard, K., \& Masatu, M. C. (2006). Outpatient process quality evaluation and the Hawthorne Effect. Social science \& medicine, 63, 2330-2340.

Lethbridge, T. C., Sim, S. E., \& Singer, J. (2005). Studying software engineers: Data collection techniques for software field studies. Empirical software engineering, 10, 311-341.

Levitt, S. D., \& List, J. A. (2007). What do laboratory experiments measuring social preferences reveal about the real world? The journal of economic perspectives, 21, 153-174.

LiveScribe. (2011). LiveScribe: never miss a word. In: http://www.livescribe.com/en-us/.

Marsden, E. (2007). Can educational experiments both test a theory and inform practice? British Educational Research Journal, 33, 565-588.

Newman, D., \& Cole, M. (2004). Can scientific research from the laboratory be of any use to teachers? Theory into Practice, 43, 260-267.

Nordgren, L. F., \& McDonnell, M. H. M. (2011). The Scope-Severity paradox: Why doing more harm Is judged to be less harmful. Social Psychological and Personality Science, 2, 97-102.

Panopto. (2011). Panopto - Capture.Publish.Share. In: http://www.panopto.com/.

Perry, M., \& Sanderson, D. (1998). Coordinating joint design work: the role of communication and artefacts. Design Studies, 19, 273-288.

Podsakoff, P. M., MacKenzie, S. B., Lee, J.-Y., \& Podsakoff, N. P. (2003). Common method biases in behavioural research: A critical review of the literature and recommended remedies. Journal of applied psychology, 88, 879-903.

Puttre, M. (1991). Product data management. Mechanical Engineering, 113, 81-83.

Reed, S. R. (1990). Structure and behaviour: Extending Duverger's Law to the Japanese case. British Journal of Political Science, 20, 335-356.

Robinson, H., Segal, J., \& Sharp, H. (2007). Ethnographically-informed empirical studies of software practice. Information and Software Technology, 49, 540-551.

Robinson, M. A. (2010). An empirical analysis of engineers' information behaviours. Journal of the American Society for Information Science and Technology, 61, 640-658.

Seitamaa-Hakkarainen, P., \& Hakkarainen, K. (2001). Composition and construction in experts' and novices' weaving design. Design Studies, 22, 47-66.

Shadish, W. R., Cook, T. D., \& Campbell, D. T. (2002). Experimental and quasi-experimental designs for generalized causal inference. Boston, US: Mifflin and Company.

Shadish, W. R., Luellen, J. K., \& Clark, M. H. (2006). Propensity scores and quasi-experiments: A testimony to the practical side of Lee Sechrest. Strengthening research methodology: Psychological measurement and evaluation, 143-157.

Snider, C., Culley, S., \& Dekoninck, E. (2013). Analysing creative behaviour in the later stage design process. Design Studies: In Press.

Song, S., \& Agogino, A. M. (2004). Insights on designers, sketching activities in new product design teams. In ASME 2004 Design Engineering Technical Conference (pp. 351-360). Salt Lake City, Utah, USA.

Torgerson, D. J., \& Torgerson, C. J. (2003). Avoiding bias in randomised controlled trials in educational research. British journal of educational studies, 51, 36-45.

Torlind, P., Sonalkar, N., Bergstrom, M., Blanco, E., Hicks, B. J., \& McAlpine, H. (2009). Lessons learned and future challenges for design observatory research. In ICED 09 International Conference on Engineering Design. Stanford, CA, USA.

VCode. (2011). VCode and VData homepage [Online]. In. Illinois: http://social.cs.uiuc.edu/projects/vcode.html.

Vygotski, L. S., \& Cole, M. (1978). Mind in society: The development of higher psychological processes. Cambridge, Massachuetts: Harvard Univ Press.

Wilkinson, L. (1999). The Task Force on Statistical Inference (1999). Statistical methods in psychology journals: Guidelines and explanations. American psychologist, 54, 594-604. 


\section{Appendix: Studies 2 and 3 briefing documents}

\section{Experimental Brief - TASK 1}

This is an individual task using the computer provided and will last for fifty minutes. Please do not talk to the other participants at this stage. You are free to use the notepad and computer provided, as well as any books or catalogues you choose in the DAC. Please search for information in order to fulfil the following brief: "You are to design a universal camera mount for use on an aerial vehicle. The aerial vehicle is to be used by an amateur photographer, primarily to take still photos. Using any means available to you search for and note down information that may help." You will be told when to begin by the researcher who will also let you know when there is 5 minutes left.

\section{Experimental Brief - TASK 2}

This is a group task using the meeting area provided and will last for fifty minutes. Please feel free to discuss and make notes etc. as you wish. You are free to use the notepad, whiteboard and notepaper provided. During this task we would like you to brainstorm ideas to fulfil the following brief. The aim of this task is to generate as many viable ideas as possible within the time available. Please record these ideas on the whiteboard as they occur but feel free to make additional notes as necessary: "Using the specification provided, develop a variety of concepts capable of mounting any camera, while slung under a helium balloon. The mount must be capable of orientating the camera to any point in a hemi-spherical plane underneath the balloon, and must be operated 
remotely." You will be told when to begin by the researcher who will also let you know when there is 5 minutes left.

\section{Brainstorming and Specification}

Produce as many ideas as possible. Consider all information that you have gathered in stage 1. Consider as many technologies, products, theories and systems as possible. Be supportive of all ideas proposed. Instead of finding faults, suggest ways that they could be improved.

Total mass of camera and mount $\quad 6 \mathrm{~kg}$

Must take a range of cameras within weight limits

Cost (cost price) of the mount $\quad £ 75$

Operational life (per charge) $\quad 1.5$ hours

Speed of operation -360 o pan $\quad \max 30 \mathrm{~s} \min 10 \mathrm{~s}$

Type of control via laptop

Range of controller $100 \mathrm{~m}$

Range of rotation 360 by 1800

Volumetric size $200 \times 200 \times 150 \mathrm{~mm}$

Balloon connection flexible

Balloon size Spherical

The design for the balloon has already been finalised, and is tolerant of any connection or interface with the camera mount. Although you should try to minimise motion in the mount where possible, you do not need to consider vibration. 


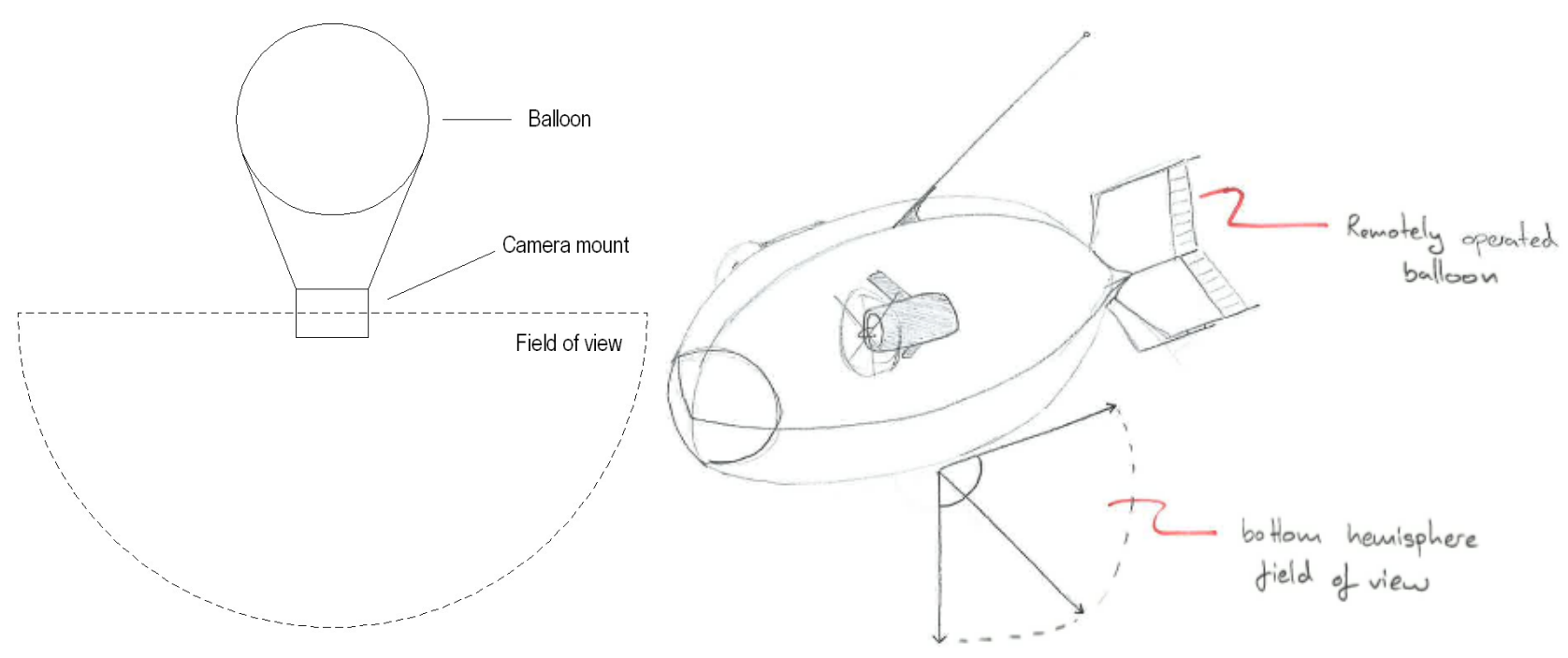

\section{Experimental Brief - TASK 3}

This is an individual task using the computer provided and will last for one and half hours. Please do not talk to the other participants at this stage. During this task we would like you to develop one (1) of the concepts discussed during your brainstorming session based on the following brief. You are free to use the computer and notepad provided as well as any books you wish from the DAC. Develop your concept to as high a level of detail as possible. Please record each action in your logbook as you proceed: "Develop an appropriate, feasible, dimensioned, detailed solution."

\section{Further details:}

Available machines for manufacture: lathe, end mill, injection moulding, and laser cutter; assembly: By hand. Your work from this stage will be given to a skilled technician, who will build a fully operational prototype. It must therefore include:

- General dimensions

- All critical dimensions

- Materials to be used

- A description of the mode of operation of all systems

- A description of the method of assembly 
- A description of how the design completes its function

- Preferred methods of manufacture

Although unfamiliar with the project, the technician will attempt to fill in any information that they need, should you not provide it. Complete as much work as you can, within the time allotted. You will be told when to begin by the researcher who will also let you know when there is 5 minutes left.

\section{Experimental Brief - TASK 4}

This is a group task using the meeting area provided and will last for fifty minutes. Please feel free to discuss and make notes etc. as you wish. You are free to use the notepad and notepaper provided (please do not use the whiteboard for this task). During this stage one member will be asked to take a team leader role and should pay particular attention to delivering the final concept as outlined below. During this task we would like you to review your designs (as developed in the previous task). The aim of this task is to select and develop one (or a combination of ideas) into a final concept to be taken forward to production. Please see the following brief: "With your colleagues, and using your detailed developed concepts, select and further develop a single, final concept that best fulfils the brief and specification. Please record this final concept on a single sheet of the provided A3 paper." You will be told when to begin by the researcher who will also let you know when there is 5 minutes left. 